FEDERAL

RESERVE

BANK of

ST. LOUIS
RESEARCH DIVISION

Working Paper Series

\title{
Debt, Inflation and Central Bank Independence
}

\author{
Fernando M. Martin
}

\author{
Working Paper 2013-017F \\ https://doi.org/10.20955/wp.2013.017
}

June 2015

\section{FEDERAL RESERVE BANK OF ST. LOUIS}

Research Division

P.O. Box 442

St. Louis, MO 63166

The views expressed are those of the individual authors and do not necessarily reflect official positions of the Federal Reserve Bank of St. Louis, the Federal Reserve System, or the Board of Governors.

Federal Reserve Bank of St. Louis Working Papers are preliminary materials circulated to stimulate discussion and critical comment. References in publications to Federal Reserve Bank of St. Louis Working Papers (other than an acknowledgment that the writer has had access to unpublished material) should be cleared with the author or authors. 


\title{
Debt, Inflation and Central Bank Independence
}

\author{
Fernando M. Martin* \\ Federal Reserve Bank of St. Louis
}

June 17, 2015

\begin{abstract}
Increasing the independence of a central bank from political influence, although ex-ante socially beneficial and initially successful in reducing inflation, would ultimately fail to lower inflation permanently. The smaller anticipated policy distortions implemented by a more independent central bank would induce the fiscal authority to decrease current distortions by increasing the deficit. Over time, inflation would increase to accommodate a higher public debt. Alternatively, imposing a strict inflation target would lower inflation permanently and insulate the primary deficit from political distortions.
\end{abstract}

Keywords: government debt, inflation, deficit, central bank independence, time-consistency, inflation targeting.

JEL classification: E52, E58, E61, E62.

\footnotetext{
*Email: fernando.m.martin@stls.frb.org. I would like to thank seminar participants at the Chicago Fed Summer Workshop on Money, Banking and Payments, the University of Victoria, the conference on "Old and New Ideas about Fiscal Policy" at LAEF, the Annual Meeting of the Society for Economic Dynamics, the Vienna Macroeconomics Workshop, Stony Brook University, the Federal Reserve Bank of St. Louis, the National Bank of Slovakia, the Bank of England, the University of Oxford, Royal Holloway University of London, the Canadian Macroeconomics Study Group, Reading University and CEMFI. I also thank Brian Bergfeld, Wan-Jung Cheng, Wei Wang and Haitao Xiang for helpful research assistance, and Francisco Ruge-Murcia for a discussion at the 2013 CMSG. I gratefully acknowledge the SFU/SSHRC Institutional Grants Committee for financial support during the initial stage of this project. The views expressed in this paper do not necessarily reflect official positions of the Federal Reserve Bank of St. Louis, the Federal Reserve System, or the Board of Governors.
} 


\section{Introduction}

Concern over political influence on the conduct of monetary policy is an important element in the design of government institutions. A widely held belief is that having an independent central bank, protected from the pressures of political expediency, is conducive to low inflation, as suggested by long-run correlations found in cross-country studies. ${ }^{1}$

Following the seminal contributions of Kydland and Prescott (1977), Barro and Gordon (1983) and Rogoff (1985), central bank independence is viewed primarily as a means to mitigate an inflation bias that may arise under discretionary policy. ${ }^{2}$ This classic argument, however, ignores the role played by the fiscal authority in ultimately shaping the overall policy response to institutional reform. ${ }^{3}$ As I shall argue below, due to the interaction of fiscal and monetary policies, increasing central bank independence, although ex-ante socially beneficial and initially successful, would ultimately fail to lower long-run inflation.

Consider an economy in which public spending is higher than what is socially optimal. Assuming monetary policy is somewhat accommodative to fiscal conditions, an expenditure bias implies inefficiently high inflation. A potentially beneficial institutional reform would be to insulate the conduct of monetary policy from political distortions by making the central bank's objectives more aligned with the preferences of private agents. After the reform, the central bank would be less willing to monetize the deficit, which would lead to a drop in inflation.

The fiscal authority would understand that, for any level of debt it decided to pass on, future monetary policy distortions would be lower when facing a more independent central bank. Since it is desirable to smooth policy distortions intertemporally (see Barro, 1979), an increase in central bank independence, which lowers future distortions for any given current policy, would provide the fiscal authority with incentives to decrease current distortions in exchange for higher future distortions. Specifically, there would be a decrease in current taxation, i.e., an increase in the deficit, which in turn, raises future distortions due to the financial burden of a larger accumulated debt. As long as the central bank remained somewhat accommodative, inflation would rise as debt increased, gradually reversing the initial effects of the reform.

Instead, if the central bank were to adhere to a monetary policy rule independent of the level of debt (e.g., a strict inflation target), then the fiscal authority would not be able to use its debt choice to affect future monetary policy distortions. In other words, the lack of monetary policy accommodation to fiscal conditions removes the mechanism through which the fiscal authority would want to trade off distortions intertemporally. As a consequence, the level of debt is kept constant and permanently lower inflation and deficit are achieved.

In this paper, I formalize the arguments presented above and provide theoretical and quantitative assessments of the effects of central bank independence. I study this issue in the context of a monetary economy based on the environment by Lagos and Wright (2005), with the addition of a government that uses distortionary taxes, money and nominal bonds to finance the provision of a valued public good. At the beginning of each period, two authorities choose government policy simultaneously: the central bank determines the money growth rate independently of the fiscal authority, which decides on taxes and expenditure; public debt evolves

\footnotetext{
${ }^{1}$ See Alesina and Summers (1993), Campillo and Miron (1997), Walsh (2008) and Waller (2011). Although the correlation is a well-established fact, the evidence on causality is mixed. In Section 4.6, I describe the empirical literature in detail and connect it to the results in this paper.

${ }^{2}$ See Lohmann (1992), Waller (1992), Walsh (1995) and Svensson (1997).

${ }^{3}$ Notable exceptions that incorporate some elements of fiscal policy to Rogoff's framework are Adam and Bili (2008) who assume fiscal policy is passive in the sense of Leeper (1991), and Niemann (2011) who assumes the fiscal authority is myopic. There is also an earlier literature on noncooperative fiscal and monetary policies (e.g., Alesina and Tabellini, 1987 and Dixit and Lambertini, 2003) that abstracts from public debt, which is key for the mechanism described in this paper.
} 
to satisfy the consolidated government budget constraint. Both authorities lack the ability to commit to policy choices beyond the current period. Policymakers care about the welfare of private agents, but, in addition, derive a political rent, which increases with the level of public expenditure. The existence of these political frictions can be motivated, for example, by a drive towards empire-building, the presence of a self-serving bureaucracy or the practice of patronage, all of which provide incentives for a larger government.

Government policy is determined by the interaction of three forces: distortion-smoothing, a time-consistency problem and political disagreement. The incentive to smooth distortions intertemporally follows the classic arguments in Barro (1979) and Lucas and Stokey (1983). Time-consistency problems arise from the interaction between debt and monetary policy, as analyzed in Martin $(2009,2011,2013)$ for the case when policy is implemented by a single benevolent unit: how much debt the government inherits affects its monetary policy since inflation reduces the real value of nominal liabilities; in turn, the anticipated response of future monetary policy affects the current demand for money and bonds, and thereby how the government today internalizes policy trade-offs. Political disagreement appears whenever the fiscal and monetary authorities derive different political rents from government spending. ${ }^{4}$

A convenient starting point for the analysis is a situation in which both authorities value the political rent equally, i.e., in which the central bank is fully influenced by the fiscal authority or, equivalently, captive to the same extent by political considerations. The degree of central bank independence is thus measured by how much the monetary authority disagrees with the fiscal authority on the value of the political rent. I focus on reforms that make the central bank value political rents less than the fiscal authority. Hence, a more independent central bank is a more benevolent monetary authority, one whose policy objectives are more aligned with private agents' preferences. In the terminology adopted by the literature, the central bank as modeled here always enjoys instrument independence, i.e., the ability to freely set policy in the pursuit of its objective, and the reforms I study involve further endowing it with goal independence, i.e., the capacity to determine its policy objective with limited influence from the fiscal authority. ${ }^{5}$

In the absence of political disagreement, the fiscal and monetary authorities behave as a single decision unit. Thus, granting the central bank instrument independence is not alone sufficient to trigger changes in policy. That is, an effective institutional reform requires endowing the central bank with both instrument and goal independence. Furthermore, when starting at the discretionary steady state, endowing the government with the ability to commit to all future decisions does not affect policy either. ${ }^{6}$ Instead, a reform that makes the central bank more independent from political distortions, i.e., more benevolent than the fiscal authority, improves social welfare and has implications for fiscal and monetary policies. In the short run, the reform leads to a drop in inflation and an increase in the primary deficit. These effects may be persistent, but in the long run, the accumulation of public debt induces an increase in inflation, back to around its original level. The results are thus consistent with the widespread belief that central bank reform leads to lower inflation, but do not support the hypothesis that independence by itself is conducive to permanently lower inflation.

The response of the fiscal authority to institutional reform is critical to account for the full policy dynamics just described. If the fiscal authority were not to revise its policy when facing a more independent central bank, the rise in debt would be largely mitigated, as the only driver of its increase would be the reduction in seigniorage. However, as argued above, it is optimal

\footnotetext{
${ }^{4}$ More generally, government authorities would disagree on desired policy whenever they each internalize policy distortions differently.

${ }^{5}$ For a discussion of instrument and goal independence, see Grilli et al. (1991) and Debelle and Fischer (1994).

${ }^{6}$ This result generalizes the findings in Martin (2011). See Proposition 1 in Section 3.5 below and the surrounding discussion. Note that there is still a role for institutional reform since the government, regardless of commitment power, is not benevolent.
} 
for the fiscal authority to increase the deficit it implements for any given level of debt, which explains both the (significant) accumulation of public debt and the eventual return of inflation to around its pre-reform level. This mechanism arises due to the explicit modeling of both public debt and fully rational government authorities, elements that distinguish this paper from previous theoretical explorations with interacting government authorities, such as Dixit and Lambertini (2003) and Niemann (2011).

The adoption of an inflation target removes a key channel through which fiscal considerations ultimately dominate the conduct of monetary policy and allows for the implementation of permanently lower inflation and deficit. This result refines the popular prescription that monetary policy should dominate fiscal policy, as first articulated by Sargent and Wallace (1981), and provides a novel motivation for the adoption of explicit inflation targets. In addition, I find that the welfare gains from implementing the optimal inflation target are non-trivial and far surpass the benefits from simply strengthening the independence of the central bank.

The analysis and results presented in this paper rely on two important modeling choices. First, I assume that increasing the independence of the central bank consists of increasing its benevolence relative to that of the fiscal authority. This is motivated by Walsh (2008) who defines central bank independence as "the freedom of monetary policymakers from direct political or government influence in the conduct of policy". The definition suggests the presence of political frictions that may lead to inefficiencies in monetary policy, but remains silent on how greater independence is to be achieved. With this in mind, I start off with an environment in which the government is not benevolent and study the implications of aligning the central bank's objectives closer to the preferences of private agents and away from those of the nonbenevolent fiscal authority. This is a more general approach than endowing the central bank with an explicit policy objective. Greater independence can in principle be achieved through various means, but its ultimate goal is always to mitigate detrimental political influence. In fact, as long as institutional reforms penalize the central bank for the implementation of policy distortions in excess of some desired amount, the main mechanism through which the fiscal authority responds to reform is still in effect, as these distortions necessarily increase with the financial obligations inherited by policymakers, i.e., the level of public debt.

Despite the apparent formal differences, the institutional reform considered here shares important conceptual similarities with the conservative central bank proposed by Rogoff (1985). In both cases, making the central bank more independent (or conservative) leads to monetary policy being less accommodative to politicians' objectives. In the classic Rogoff study, the reform explicitly means not succumbing to the ex-post temptation to lower the unemployment rate through higher inflation; here, it means lowering the tolerance for policy distortions, which implies mitigating the ex post incentive to partially default on accumulated debt through inflation. In both cases, the notion of independence includes the assumption that central bankers will not be removed from office for acting according to objectives which are misaligned with politicians' preferences. And in both cases, the welfare of private agents increases with a more independent central bank.

Second, I assume that the fiscal and monetary authorities choose their current actions simultaneously. The idea is to study a benchmark case in which neither authority dominates the other, which would be the case if, instead, we were to assume that one authority moves first. In reality, fiscal and monetary agencies react to each other. Throughout the year, central banks hold frequent meetings in which policy is evaluated and possibly revised, while fiscal authorities have mechanisms to amend annual budgets ex-post (e.g., in the U.S. these take the form of supplemental appropriation and emergency bills). Thus, it is not evident that one authority has an inherent or institutionalized first-mover advantage over the other, and it seems natural to assume that neither sets policy before the other has done so as well. Note that an effective inflation target, as described above, involves more than granting the central bank first-mover 
advantage in a period, as it consists of a commitment to a non-state-contingent rule, today and in the future.

There are two recent and closely related papers that also model a fiscal and a monetary authority with limited commitment that choose actions simultaneously. Niemann (2011) studies the desirability of delegating monetary policy to a conservative central banker, assuming that the fiscal authority is myopic, i.e., does not internalize how future policies react to changes in current policy. When the model is calibrated so that steady state public debt is non-negative, Niemann finds that this reform would reduce welfare, which contrasts with the results presented here. Niemann et al. (2013) argue that the money growth rate and the nominal interest rate may not be equivalent policy instruments when the monetary and fiscal authorities disagree on how much to discount the future.

The paper is organized as follows. Section 2 describes the economy. Section 3 characterizes government policy and derives theoretical results. Section 4 provides a quantitative analysis, discusses the empirical applicability of the paper's findings and suggests an explanation for the rise of public debt in the 1980s. Section 5 concludes.

\section{A Monetary Framework}

\subsection{Environment}

Consider the following variant of the monetary framework proposed by Lagos and Wright (2005). The environment described in this section is similar to the one studied by Martin (2011). A key difference with that paper is that here, as detailed in Section 3, government policy is implemented by two distinct, generally non-benevolent, authorities.

There is a continuum of infinitely-lived agents, which discount the future by factor $\beta \in(0,1)$. Each period, two competitive markets open in sequence, a "day" and a "night" market, where perishable goods are produced and consumed. ${ }^{7}$ At the beginning of every period, agents receive an idiosyncratic shock that determines their role in the day market. With probability $\eta \in(0,1)$ an agent wants to consume but cannot produce the day-good, $x$, while with probability $1-\eta$ an agent can produce but does not want to consume. A consumer derives utility $u(x)$, where $u$ is twice continuously differentiable, satisfies Inada conditions and $u_{x x}<0<u_{x}$. A producer incurs in utility cost $\phi x$, where $\phi>0$. Agents lack commitment and are anonymous, in the sense that private trading histories are unobservable. Thus, credit transactions between consumers and producers are not possible. Since there is a double coincidence of wants problem, some medium of exchange is essential for trade to occur - see Kocherlakota (1998), Wallace (2001) and Shi (2006).

At night, all agents can produce and consume the night-good, $c$. The production technology is assumed to be linear in hours worked, $n$. Utility from consumption is given by $U(c)$, where $U$ is twice continuously differentiable, satisfies Inada conditions and $U_{c c}<0<U_{c}$. Disutility from labor is given by $\alpha n$, where $n$ is hours worked and $\alpha>0$.

There is a government that supplies a valued public good $g$ at night. To finance its expenditure, the government may use proportional labor taxes $\tau$, print fiat money at rate $\mu$ and issue one-period nominal bonds, which are redeemable in fiat money. The public good is transformed one-to-one from the night-good. Agents derive utility from the public good according to $v(g)$, where $v$ is twice continuously differentiable, satisfies Inada conditions and $v_{g g}<0<v_{g}$.

\footnotetext{
${ }^{7}$ See Martin (2013) for the qualitative and quantitative implications on government policy of assuming alternative day market arrangements, specifically, allowing for decentralized trade and bargaining, and for means of payment to be financially intermediated.
} 
From the perspective of private agents, the first-best allocation is given by $\{\hat{x}, \hat{c}, \hat{g}\} \in \mathbb{R}_{+}^{3}$ such that $u_{x}(\hat{x})=\phi$ and $U_{c}(\hat{c})=v_{g}(\hat{g})=\alpha$. As elaborated below, the government will in general not be benevolent and will disagree with private agents on the optimal level of public expenditure.

Government policy choices for the period are announced at the beginning of each day, before agents' idiosyncratic shocks are realized. The government only actively participates in the night market, i.e., taxes are levied on hours worked at night and open market operations are conducted in the night market. As in Aruoba and Chugh (2010), Berentsen and Waller (2011) and Martin (2011, 2013), public bonds are book-entries in the government's record. Since bonds are not physical objects and the government does not participate in the day market (i.e., cannot intermediate or provide third-party verification), bonds are not used as a medium of exchange in the day market and thus, money is essential. ${ }^{8}$

All nominal variables - except for bond prices - are normalized by the aggregate money stock. Thus, today's aggregate money supply is equal to 1 and tomorrow's is $1+\mu$. The consolidated government budget constraint is

$$
1+B+p_{c} g=p_{c} \tau n+(1+\mu)\left(1+q B^{\prime}\right)
$$

where $B$ is the current aggregate bond-money ratio, $p_{c}$ is the - normalized - market price of the night-good $c$, and $q$ is the price of a bond that earns one unit of fiat money in the following night market. "Primes" denote variables evaluated in the following period. Thus, $B^{\prime}$ is tomorrow's aggregate bond-money ratio. For consistency and simplicity of exposition, below, I will refer to $p_{c}$ as night-good price and $B$ as the level of debt, with the understanding that both variables are normalized by the aggregate money stock.

The government budget constraint (1) restricts government policy choices for the period, $\left\{B^{\prime}, \mu, \tau, g\right\}$, given the inherited debt level $B$ and the fact that private agents respond optimally to current and (anticipated) future policy, as reflected in prices and the labor supply. Notably, the nominal stock of money and bonds do not need to grow at the same rate. I.e., outside a steady state, the bond-to-money ratio does not have to be constant over time and the government is free to choose it every period, as long as it satisfies (1) in a monetary equilibrium.

\subsection{Monetary Equilibrium}

Let $V(m, b)$ be the value of entering the day market with (normalized) money balances $m$ and bond balances $b$. Upon entering the night market, the composition of an agent's nominal portfolio is irrelevant, since bonds are redeemed in fiat money at par. Thus, let $W(z)$ be the value of entering the night market with total (normalized) nominal balances $z$.

In the day market, consumers and producers exchange money for goods at (normalized) price $p_{x}$. Let $x$ be the quantity consumed and $\kappa$ the quantity produced. The problem of a consumer is

$$
V^{c}(m, b)=\max _{x} u(x)+W\left(m+b-p_{x} x\right)
$$

\footnotetext{
${ }^{8}$ It is convenient but not necessary to assume that bonds cannot be used to purchase goods in the day. What is critical for coexistence of money and bonds in equilibrium is that they are not perfect substitutes. One could, for example, allow a fraction of an agent's bond holdings to support transactions in the day, in the spirit of Kiyotaki and Moore (2002). Another possibility would be to allow consumers and producers to exchange money for bonds before the day market opens, either in a secondary market as in Berentsen and Waller (2011) or through a financial intermediary. The results in this paper do not hinge on the particulars of how liquidity is defined or reallocated in the day market, as long as the rate of return on fiat money is the determinant of how liquidity-constrained consumers are.
} 
subject to $p_{x} x \leq m$. The problem of a producer is

$$
V^{p}(m, b)=\max _{\kappa}-\phi \kappa+W\left(m+b+p_{x} \kappa\right)
$$

Given $V(m, b)=\eta V^{c}(m, b)+(1-\eta) V^{p}(m, b)$ and total nominal balances $z$, the problem of an agent in the night market is

$$
W(z)=\max _{c, n, m^{\prime}, b^{\prime}} U(c)+v(g)-\alpha n+\beta V\left(m^{\prime}, b^{\prime}\right)
$$

subject to $p_{c} c+(1+\mu)\left(m^{\prime}+q b^{\prime}\right)=p_{c}(1-\tau) n+z$.

The derivation of the conditions characterizing a monetary equilibrium is standard, so some details are omitted for brevity. Using the budget constraint at night to remove labor from the agent's problem, the first-order conditions are

$$
\begin{aligned}
U_{c}-\frac{\alpha}{(1-\tau)} & =0 \\
-\frac{\alpha(1+\mu)}{p_{c}(1-\tau)}+\beta V_{m}^{\prime} & =0 \\
-\frac{\alpha q(1+\mu)}{p_{c}(1-\tau)}+\beta V_{b}^{\prime} & =0 .
\end{aligned}
$$

Focusing on a symmetric equilibrium, we can follow Lagos and Wright (2005) to show that (3) and (4) imply all agents exit the night market with the same money and bond balances. ${ }^{9}$ Thus, in equilibrium, $m^{\prime}=1$ and $b^{\prime}=B^{\prime}$. The night-resource constraint is $c+g=n$, where, with a slight abuse in notation, $n$ is aggregate labor. Private consumption $c$ and public consumption $g$ are the same for all agents, whereas individual labor depends on whether an agent was a consumer or a producer during the day. From (3) and (4) we get $q=V_{b}^{\prime} / V_{m}^{\prime}$, i.e., agents need to be compensated for the lower liquidity services provided by bonds, relative to fiat money, in the following day market.

The night-value function $W$ is linear, $W_{z}=\frac{\alpha}{p_{c}(1-\tau)}$, which simplifies the agent's problem in the day. The problem of a consumer implies $u_{x}-\frac{\alpha p_{x}}{p_{c}(1-\tau)}-\xi p_{x}=0$, where $\xi$ is the Lagrange multiplier associated with the liquidity constraint, $m-p_{x} x \geq 0$. A producer in the day is indifferent about producing an extra unit of day-output when $\phi=\frac{\alpha p_{x}}{p_{c}(1-\tau)} \cdot{ }^{10}$ The day market clearing condition is $\eta=(1-\eta) p_{x} \kappa$, which, given the day-resource constraint $\eta x=(1-\eta) \kappa$, implies $p_{x}=\frac{1}{x}$. Thus, the equilibrium in the day market is characterized by

$$
\phi x=\frac{\alpha}{p_{c}(1-\tau)} .
$$

The left-hand side of (5) is the marginal utility cost for a producer, expressed in terms of daypurchasing power; the right-hand side is the real marginal benefit of arriving at night with an extra unit of nominal assets. Since producers get compensated with money for their production costs, these two expressions are equated in equilibrium. From the envelope conditions, and using (5) to simplify, we get $V_{m}=x\left(\eta u_{x}+(1-\eta) \phi\right)$ and $V_{b}=\phi x$.

\footnotetext{
${ }^{9}$ This follows from the linearity in night-labor disutility. In a recent paper, Wong (2014) extends this result to a more general class of preferences. In addition, note that since $V$ is linear in $b$, a non-degenerate distribution of bonds is possible in equilibrium. Here, we focus on symmetric equilibria. See Aruoba and Chugh (2010) and Martin (2011) for related discussions.

${ }^{10}$ Note that this is the condition that emerges when we consider a more general convex cost function $f(\kappa)$ and let $f(\kappa) \rightarrow \phi \kappa$.
} 
Using conditions (2)-(5) and the expressions for $V_{m}$ and $V_{b}$, we can write policy variables and prices as functions of allocations, which will simplify the formulation of the government's problem below. Specifically, we obtain

$$
\begin{aligned}
1+\mu & =\frac{\beta x^{\prime}\left(\eta u_{x}^{\prime}+(1-\eta) \phi\right)}{\phi x} \\
\tau & =1-\frac{\alpha}{U_{c}} \\
p_{c} & =\frac{U_{c}}{\phi x} \\
q & =\frac{\phi}{\eta u_{x}^{\prime}+(1-\eta) \phi} .
\end{aligned}
$$

We can now define inflation and interest rates. Let $1+\pi \equiv \frac{(1+\mu) P^{\prime}}{P}$, where $P$ is the (normalized) aggregate price level. Given day-good and night-good expenditure shares $\varsigma_{x}$ and $\varsigma_{c}$, respectively, the aggregate price level is defined as $P \equiv \varsigma_{x} p_{x}+\varsigma_{c} p_{c}$. Thus, using $p_{x}=\frac{1}{x}$, (6) and (8) we obtain

$$
1+\pi=\frac{\beta\left(\eta u_{x}^{\prime}+(1-\eta) \phi\right)\left(\varsigma_{x} \phi+\varsigma_{c} U_{c}^{\prime}\right)}{\phi\left(\varsigma_{x} \phi+\varsigma_{c} U_{c}\right)} .
$$

Note that the inflation rate $\pi$ is not equal to the money growth rate $\mu$, except in steady state. As usual, the nominal interest rate is defined as the inverse of the bond price. Thus, let $1+i \equiv \frac{1}{q}$. Using the Fisher equation, we get an expression for the real interest rate, $1+r=\frac{\left(\varsigma_{x} \phi+\varsigma_{c} U_{c}\right)}{\beta\left(\varsigma_{x} \phi+\varsigma_{c} U_{c}^{\prime}\right)}$. In steady state, the (gross) real interest rate is equal to the inverse of the discount factor, but in general, it varies with the allocation of the night-good.

\section{A Theory of Central Bank Independence}

\subsection{The government}

Government policy is conducted by two distinct agencies: a fiscal authority $(F)$ and a monetary authority or central bank $(M) .{ }^{11}$ The former decides taxes and expenditure, and the latter manages the stock of money. Debt is determined residually, to satisfy the consolidated government budget constraint. Policy choices for each period are made simultaneously at the beginning of the day market, before agents' idiosyncratic shocks are realized. Both authorities lack the ability to commit to policy choices in future periods. To characterize government policy with limited commitment, I adopt the notion of Markov-perfect equilibrium, i.e., where policy functions depend only on fundamentals. ${ }^{12}$

The political environment is built on the three basic assumptions postulated by Persson et al. (2000) for the positive analysis of government policy in modern democracies: (i) actors, including politicians, are not benevolent; (ii) citizens delegate policy decisions to political agents; and (iii) there is no outside enforcement. The last assumption is accounted for by limited commitment in the conduct of policy, as described above. To account for the other two assumptions, an agency's period payoff contains two elements: first, the ex-ante period utility of private agents;

\footnotetext{
${ }^{11}$ Throughout the paper, the word "government" refers to government as a whole, that is, the aggregation or consolidation of the fiscal and monetary authorities. Hence, for example, "government policy" is short for "fiscal and monetary policy" and "government budget constraint" stands for "consolidated government budget constraint".

${ }^{12}$ See Maskin and Tirole (2001) for a definition and justification of this solution concept. For recent applications to dynamic policy games see Ortigueira (2006), Klein et al. (2008), Díaz-Giménez et al. (2008), Azzimonti et al. (2009), Martin (2009, 2010, 2011, 2013), Niemann (2011) and Niemann et al. (2013).
} 
and second, a political rent, which is a function of the size of government. The idea is that the government is typically self-serving (non-benevolent), but still requires the (partial) support of private agents.

Specifically, the period utility of authority $i=\{F, M\}$ is given by $\mathcal{U}(x, c, g)+\mathcal{R}_{i}(g)$, where $\mathcal{U}(x, c, g) \equiv \eta(u(x)-\phi x)+U(c)+v(g)-\alpha(c+g)$ is the ex-ante period utility of an agent, and $\mathcal{R}_{i}(g)$ is the authority's political rent, as a function of public-good provision. ${ }^{13}$ The rent is a purely utility benefit, with no direct resource cost. To ensure the problem of the government is well-behaved, the function $\mathcal{R}_{i}(g)$ is assumed to satisfy a set of regularity conditions. In essence, the requirement is that the period payoff for each authority be strictly increasing and concave in $g$ for a relevant range.

Assumption 1 For $i=\{F, M\}$, there exists $\tilde{g}_{i} \geq \hat{g}$ such that: (i) $v_{g}(g)-\alpha+\mathcal{R}_{i, g}(g)>0$ for all $g \in\left[0, \tilde{g}_{i}\right)$ and $v_{g}\left(\tilde{g}_{i}\right)-\alpha+\mathcal{R}_{i, g}\left(\tilde{g}_{i}\right)=0$; and (ii) $v_{g g}(g)+\mathcal{R}_{i, g g}(g)<0$ for all $g \geq 0$.

The critical values $\tilde{g}_{F}$ and $\tilde{g}_{M}$ are the optimal levels of public expenditure from the perspective of the fiscal and monetary authorities, respectively. As long as an authority derives political rents, its preferred spending level will be higher than that of private agents, $\hat{g}$.

There are several straightforward examples that satisfy Assumption 1 and have a natural economic interpretation. A trivial example, of course, is $\mathcal{R}_{i}(g)=0$, in which case the government authority is benevolent. Now suppose $\mathcal{R}_{i}(g)=\left(\omega_{i}^{-1}-1\right) g$, with $\omega_{i} \in(0,1]$, which will be the working assumption for some theoretical and numerical results. In this case, the authority weights being benevolent by $\omega_{i}$ and maximizing the size of government by $1-\omega_{i}$. Finally, consider $\mathcal{R}_{i}(g)=-v(g)+\left(\omega_{i} \varrho_{i}\right)^{-1} g^{\varrho_{i}}$, with $\omega_{i}>0$ and $\varrho_{i} \in(0,1)$. In this case, the authority fully dismisses the benefit provided to agents from public expenditure and faces diminishing returns from the political rent.

\subsection{Problem of government authorities and equilibrium}

The literature on optimal policy with distortionary instruments typically adopts what is known as the primal approach, which consists of using the first-order conditions of the agent's problem to substitute prices and policy instruments for allocations in the government budget constraint. Following this approach, the problem of a government with limited commitment can be written in terms of choosing debt and allocations. This is the approach I will follow below.

From (6), for a given $x^{\prime}$ (which in equilibrium is a function of debt choice, $B^{\prime}$ ), a higher $\mu$ clearly implies a lower $x$. In other words, given current debt policy and future monetary policy, the allocation of the day-good is a function of current monetary policy. Thus, we can interchangeably refer to variations in the day-good allocation and variations in current monetary policy. Similarly, from (7) a higher tax rate is equivalent to lower night-good consumption, $c$.

Using (6)-(9) and the night-resource constraint, $c+g=n$, to replace variables in (1), we can write the consolidated government budget constraint in a monetary equilibrium as

$$
\left(U_{c}-\alpha\right) c-\alpha g+\beta \eta x^{\prime}\left(u_{x}^{\prime}-\phi\right)+\beta \phi x^{\prime}\left(1+B^{\prime}\right)-\phi x(1+B)=0,
$$

which can be expressed compactly as $\varepsilon\left(B, B^{\prime}, x, x^{\prime}, c, g\right)=0$.

The fiscal (monetary) authority takes as given the policy of the monetary (fiscal) authority for the current period and the policies of both authorities in all future periods. Let $\{\mathcal{B}(B), \mathcal{X}(B), \mathcal{C}(B), \mathcal{G}(B)\}$ be the debt, day-good, night-good and public-good allocation implemented in a Markov-perfect equilibrium, as a function of the inherited level of debt. In

\footnotetext{
${ }^{13}$ Note that we simplify the expected day-utility, $\eta u(x)-(1-\eta) \phi \kappa$ by using the day-resource constraint, $\eta x=(1-\eta) \kappa$. Also note the use of the night market resource constraint, $c+g=n$.
} 
the formulation below, the problem of each government authority is written as a best-response to the other current authority and both future authorities, which are all playing equilibrium policies.

Let $\Gamma \in[-1, \bar{B}]$ be the set of possible debt levels, where $\bar{B}$ is large enough so that it does not constrain government behavior. The lower bound on $\Gamma$ is not restrictive either, as shown in Proposition 2 below - see also related results in Martin $(2011,2013)$. The problem of the fiscal authority can be written as choosing $c$ and $g$, given current monetary policy $x=\mathcal{X}(B)$ and future fiscal and monetary policies which induce net present value $\mathcal{F}(B)$. Debt is determined residually to satisfy (11), but the fiscal authority understands that the choice of taxes and expenditure affect it. The problem of the fiscal authority can be written as follows:

$$
\max _{B^{\prime}, c, g} \mathcal{U}(\mathcal{X}(B), c, g)+\mathcal{R}_{F}(g)+\beta \mathcal{F}\left(B^{\prime}\right)
$$

subject to $\varepsilon\left(B, B^{\prime}, \mathcal{X}(B), \mathcal{X}\left(B^{\prime}\right), c, g\right)=0$ and given

$$
\mathcal{F}\left(B^{\prime}\right) \equiv \mathcal{U}\left(\mathcal{X}\left(B^{\prime}\right), \mathcal{C}\left(B^{\prime}\right), \mathcal{G}\left(B^{\prime}\right)\right)+\mathcal{R}_{F}\left(\mathcal{G}\left(B^{\prime}\right)\right)+\beta \mathcal{F}\left(\mathcal{B}\left(B^{\prime}\right)\right),
$$

The problem of the monetary authority can be written analogously as choosing $x$, given current fiscal policy $c=\mathcal{C}(B)$ and $g=\mathcal{G}(B)$, and future fiscal and monetary policies which induce net present value $\mathcal{M}(B)$. Again, debt is determined as a residual to satisfy (11), but the central bank understands it can affect the level of debt by varying the money growth rate, i.e., the allocation of the day-good. The problem of the monetary authority is then:

$$
\max _{B^{\prime}, x} \mathcal{U}(x, \mathcal{C}(B), \mathcal{G}(B))+\mathcal{R}_{M}(\mathcal{G}(B))+\beta \mathcal{M}\left(B^{\prime}\right)
$$

subject to $\varepsilon\left(B, B^{\prime}, x, \mathcal{X}\left(B^{\prime}\right), \mathcal{C}(B), \mathcal{G}(B)\right)=0$ and given

$$
\mathcal{M}\left(B^{\prime}\right) \equiv \mathcal{U}\left(\mathcal{X}\left(B^{\prime}\right), \mathcal{C}\left(B^{\prime}\right), \mathcal{G}\left(B^{\prime}\right)\right)+\mathcal{R}_{M}\left(\mathcal{G}\left(B^{\prime}\right)\right)+\beta \mathcal{M}\left(\mathcal{B}\left(B^{\prime}\right)\right) .
$$

In the problem of both government authorities, condition (11) implicitly solves for $B^{\prime}$ for any given deviation of the corresponding authority from equilibrium. In other words, each authority can freely employ its endowed instruments in the pursuit of its own objective, understanding that this choice will affect end-of-period debt. This realization is critical, as the policies implemented by future authorities depend on the inherited level of debt and hence, affect the intertemporal trade-offs faced by current policymakers.

We are now ready to define an equilibrium in this economy.

Definition 1 A Markov-Perfect Monetary Equilibrium (MPME) is a set of functions $\{\mathcal{B}, \mathcal{X}$, $\mathcal{C}, \mathcal{G}, \mathcal{F}, \mathcal{M}\}: \Gamma \rightarrow \Gamma \times \mathbb{R}_{+}^{3} \times \mathbb{R}^{2}$, such that for all $B \in \Gamma$ :

(i) $\{\mathcal{B}(B), \mathcal{C}(B), \mathcal{G}(B)\}=\operatorname{argmax}_{B^{\prime}, c, g} \mathcal{U}(\mathcal{X}(B), c, g)+\mathcal{R}_{F}(g)+\beta \mathcal{F}\left(B^{\prime}\right)$ subject to $\varepsilon\left(B, B^{\prime}, \mathcal{X}(B), \mathcal{X}\left(B^{\prime}\right), c, g\right)=0$;

(ii) $\{\mathcal{B}(B), \mathcal{X}(B)\}=\operatorname{argmax}_{B^{\prime}, x} \mathcal{U}(x, \mathcal{C}(B), \mathcal{G}(B))+\mathcal{R}_{M}(\mathcal{G}(B))+\beta \mathcal{M}\left(B^{\prime}\right)$ subject to $\varepsilon\left(B, B^{\prime}, x, \mathcal{X}\left(B^{\prime}\right), \mathcal{C}(B), \mathcal{G}(B)\right)=0$;

(iii) $\varepsilon(B, \mathcal{B}(B), \mathcal{X}(B), \mathcal{X}(\mathcal{B}(B)), \mathcal{C}(B), \mathcal{G}(B))=0$;

(iv) $\mathcal{F}(B)=\mathcal{U}(\mathcal{X}(B), \mathcal{C}(B), \mathcal{G}(B))+\mathcal{R}_{F}(\mathcal{G}(B))+\beta \mathcal{F}(\mathcal{B}(B))$;

(v) $\mathcal{M}(B)=\mathcal{U}(\mathcal{X}(B), \mathcal{C}(B), \mathcal{G}(B))+\mathcal{R}_{M}(\mathcal{G}(B))+\beta \mathcal{M}(\mathcal{B}(B))$. 


\subsection{Characterization}

From this point on, I will focus on policy functions which are differentiable. ${ }^{14}$ Let $\lambda_{F}$ be the Lagrange multiplier associated with the constraint in the fiscal authority's problem. The first-order conditions are

$$
\begin{aligned}
\mathcal{F}_{B}^{\prime}+\lambda_{F} \phi x^{\prime}+\lambda_{F}\left\{\eta\left(u_{x x}^{\prime} x^{\prime}+u_{x}^{\prime}-\phi\right)+\phi\left(1+B^{\prime}\right)\right\} \mathcal{X}_{B}^{\prime} & =0 \\
U_{c}-\alpha+\lambda_{F}\left(U_{c}-\alpha+U_{c c} c\right) & =0 \\
v_{g}-\alpha+\mathcal{R}_{F, g}-\lambda_{F} \alpha & =0 .
\end{aligned}
$$

The envelope condition implies $\mathcal{F}_{B}=-\lambda_{F} \phi x+\left\{\eta\left(u_{x}-\phi\right)-\lambda_{F} \phi(1+B)\right\} \mathcal{X}_{B}$.

Using $\lambda_{M}$ as the Lagrange multiplier associated with the constraint in the monetary authority's problem, the first-order conditions are

$$
\begin{aligned}
\mathcal{M}_{B}^{\prime}+\lambda_{M} \phi x^{\prime}+\lambda_{M}\left\{\eta\left(u_{x x}^{\prime} x^{\prime}+u_{x}^{\prime}-\phi\right)+\phi\left(1+B^{\prime}\right)\right\} \mathcal{X}_{B}^{\prime} & =0 \\
\eta\left(u_{x}-\phi\right)-\lambda_{M} \phi(1+B) & =0 .
\end{aligned}
$$

The envelope condition implies $\mathcal{M}_{B}=-\lambda_{M} \phi x+\left\{U_{c}-\alpha+\lambda_{M}\left(U_{c}-\alpha+U_{c c} c\right)\right\} \mathcal{C}_{B}+\left\{v_{g}-\alpha+\right.$ $\left.\mathcal{R}_{M, g}-\lambda_{M} \alpha\right\} \mathcal{G}_{B}$.

From (14) and (16) we get expressions for the Lagrange multipliers: $\lambda_{F}=\frac{v_{g}-\alpha+\mathcal{R}_{F, g}}{\alpha}$ and $\lambda_{M}=\frac{\eta\left(u_{x}-\phi\right)}{\phi(1+B)}$. Both multipliers have the usual interpretation of measuring the size of distortions created by government policy. Using these expressions, together with (13) and the envelope conditions, we can rewrite (12) and (15), respectively:

$$
\begin{aligned}
\phi x^{\prime}\left(\lambda_{F}-\lambda_{F}^{\prime}\right)+\lambda_{F} \mathcal{X}_{B}^{\prime}\left\{\eta\left(u_{x x}^{\prime} x^{\prime}+u_{x}^{\prime}-\phi\right)+\phi\left(1+B^{\prime}\right)\right\} & \\
+\left(\lambda_{M}^{\prime}-\lambda_{F}^{\prime}\right) \phi\left(1+B^{\prime}\right) \mathcal{X}_{B}^{\prime} & =0
\end{aligned}
$$

and

$$
\begin{gathered}
\phi x^{\prime}\left(\lambda_{M}-\lambda_{M}^{\prime}\right)+\lambda_{M} \mathcal{X}_{B}^{\prime}\left\{\eta\left(u_{x x}^{\prime} x^{\prime}+u_{x}^{\prime}-\phi\right)+\phi\left(1+B^{\prime}\right)\right\} \\
+\left(\lambda_{M}^{\prime}-\lambda_{F}^{\prime}\right)\left\{\left(U_{c}^{\prime}-\alpha+U_{c c}^{\prime} c^{\prime}\right) \mathcal{C}_{B}^{\prime}-\alpha \mathcal{G}_{B}^{\prime}\right\}+\left(\mathcal{R}_{M, g}^{\prime}-\mathcal{R}_{F, g}^{\prime}\right) \mathcal{G}_{B}^{\prime}=0 .
\end{gathered}
$$

Conditions (17) and (18) are known as Generalized Euler Equations (GEEs) due to the presence of the derivatives of equilibrium policy functions. A MPME is characterized by a set of functions $\{\mathcal{B}, \mathcal{X}, \mathcal{C}, \mathcal{G}\}$ that satisfy (11), (13), (17) and (18) for all $B \in \Gamma$.

\subsection{Policy trade-offs}

Government policy is determined by the interaction of three main forces: distortion-smoothing, a time-consistency problem and political disagreement. Let us go over each of these in turn, by analyzing the terms in the fiscal and monetary GEEs.

The first term in (17) and (18), $\phi x^{\prime}\left(\lambda_{i}-\lambda_{i}^{\prime}\right)$ for $i=\{F, M\}$, is the standard trade-off between current and future distortions. This is the basis of the classic tax-smoothing argument, due to Barro (1979), which involves setting this wedge as close to zero as possible. Here, the intertemporal distortion wedge will be weighted against the time-consistency problem and the political disagreement.

\footnotetext{
${ }^{14}$ This is a refinement that rules out equilibria where discontinuities in policy are not rooted in the environment fundamentals, but are rather an artifact of the infinite horizon. For an analysis and discussion of non-differentiable Markov-perfect equilibria see Krusell and Smith (2003) and Martin (2009). See also Martin (2011) for further discussion in a similar context.
} 
Note that zero policy distortions are not implemented for any $B \in \Gamma$. From (13), (14) and (16), $\lambda_{F}=\lambda_{M}=0$ if and only if the current allocation is $\left\{\hat{x}, \hat{c}, \tilde{g}_{F}\right\}$, i.e., first-best day-good and night-good consumption, and optimal public-good provision from the perspective of the fiscal authority. The government will not implement this "first-best" allocation in the current period if there are distortions in the future (i.e., if $\lambda_{i}^{\prime}>0$ ). In order to eliminate all policy distortions, government authorities need to: contract the money supply at the discount rate (so that the opportunity cost of holding fiat money is zero); impose zero taxes; and provide the fiscal authority's preferred level of expenditure, $\tilde{g}_{F}$. To achieve this, the government needs to start-off with sufficient claims on the private sector (negative debt). From (11), the level of debt that implements the first-best allocation is $\tilde{B}=-1-\frac{\alpha \tilde{g}_{F}}{(1-\beta) \phi \hat{x}}$, which is outside of $\Gamma{ }^{15}$

The time-consistency problem arises from the interaction between monetary policy and debt. First, the monetary authority has an incentive to inflate away the government's inherited nominal liabilities, at the cost of distorting the allocation of the day-good. Given $\lambda_{M}>0$, condition (16) states that an increase in beginning-of-period debt, $B$, implies a decrease in daygood consumption, $x$. In other words, the incentive to use inflation increases with the level of debt and thus, $\mathcal{X}_{B}<0$. This is the channel through which debt affects monetary policy. The government authorities' limited commitment introduces an additional term, $\lambda_{i} \mathcal{X}_{B}^{\prime}\left\{\eta\left(u_{x x}^{\prime} x^{\prime}+\right.\right.$ $\left.\left.u_{x}^{\prime}-\phi\right)+\phi\left(1+B^{\prime}\right)\right\}$ in both (17) and (18). From the envelope conditions of the agent's problem in the day (see Section 2.2), we have $V_{m}=x\left(\eta u_{x}+(1-\eta) \phi\right)$ and $V_{b}=\phi x$. Thus, the term multiplying $\lambda_{i} \mathcal{X}_{B}^{\prime}$ in (17) and (18), $\eta\left(u_{x x}^{\prime} x^{\prime}+u_{x}^{\prime}-\phi\right)+\phi\left(1+B^{\prime}\right)$, is equal to $\frac{d V_{m}^{\prime}}{d x^{\prime}}+\frac{d V_{b}^{\prime}}{d x^{\prime}} B^{\prime}$, which represents the change in the marginal value of money and bonds due to an increase in the day good allocation, evaluated tomorrow.

Assuming $\lambda_{i} \mathcal{X}_{B}^{\prime}<0$, the sign of the second term (17) and (18) will determine how the time-consistency problem affects the intertemporal substitution of policy distortions. Suppose the model primitives are such that $\frac{d V_{m}}{d x}=\eta\left(u_{x x} x+u_{x}\right)+(1-\eta) \phi<0$ and focus on $B>0$. On the one hand, if the government as a whole, through the actions of the fiscal and monetary authorities, increases the debt today, $\frac{d V_{m}^{\prime}}{d x^{\prime}} \mathcal{X}_{B}^{\prime}>0$ implies there is an increase in tomorrow's marginal value of money. That is, agents tomorrow, facing higher inflation due to higher debt, would have preferred to have arrived with more money. Thus, the current demand for money increases, which relaxes the consolidated government budget constraint today. On the other hand, $\frac{d V_{b}^{\prime}}{d x^{\prime}} \mathcal{X}_{B}^{\prime}=\phi \mathcal{X}_{B}^{\prime}<0$, i.e., increasing debt today implies higher future inflation, which reduces the current demand for bonds. In other words, the interest rate paid on debt increases, which tightens the consolidated government budget constraint. For low levels of debt, the former effect dominates, providing an incentive to increase the debt, whereas for large levels of debt the latter effect dominates, providing an incentive to decrease debt. The gains from these incentives are mitigated by the losses due to lower intertemporal distortion smoothing, i.e., larger wedges $\lambda_{F}-\lambda_{F}^{\prime}$ and $\lambda_{M}-\lambda_{M}^{\prime}$, and interact with anticipated variations in political payoffs.

Although the fiscal and monetary authorities are by construction independent, in the sense that they each control different policy instruments, this independence is only meaningful when they disagree on the political rent derived from their activities. The third term in the fiscal GEE (17), $\left(\lambda_{M}^{\prime}-\lambda_{F}^{\prime}\right) \phi\left(1+B^{\prime}\right) \mathcal{X}_{B}^{\prime}$, arises from differences in the preference for public-good provision. Specifically, $\phi\left(1+B^{\prime}\right) \mathcal{X}_{B}^{\prime}$ measures the future effect on the government budget constraint due to a change in monetary policy induced by higher debt. This effect is weighted by the wedge $\lambda_{M}^{\prime}-\lambda_{F}^{\prime}$, given that the fiscal authority does not control monetary policy and disagrees with the central bank on how to allocate resources. Similarly, the third and fourth terms in the monetary GEE (18) also appear due to political disagreement. The term $\left(U_{c}^{\prime}-\alpha+U_{c c}^{\prime} c^{\prime}\right) \mathcal{C}_{B}^{\prime}-\alpha \mathcal{G}_{B}^{\prime}$ measures the future effect on the government budget constraint due to a change in fiscal policy induced by

\footnotetext{
${ }^{15}$ Another possibility is that the government implements the first-best allocation by continually rolling over the debt, but this policy (a Ponzi scheme) is inconsistent with equilibrium. See a proof and related discussion in Martin (2011, 2013).
} 
higher debt. This effect is weighted by the wedge $\lambda_{M}^{\prime}-\lambda_{F}^{\prime}$, given that the monetary authority does not control fiscal policy and disagrees with the fiscal authority on how to allocate resources. The term $\left(\mathcal{R}_{M, g}^{\prime}-\mathcal{R}_{F, g}^{\prime}\right) \mathcal{G}_{B}^{\prime}$ in (18) states the disagreement in the level of future public-good provision, i.e., the political rents that the central bank cannot directly control.

\subsection{Steady state}

In steady state $\left\{B^{*}, x^{*}, c^{*}, g^{*}\right\}$, the fiscal and monetary GEEs can be rearranged as follows

$$
\begin{aligned}
\left(1+\lambda_{F}^{*}\right)\left(u_{x}^{*}-\phi\right)+\lambda_{F}^{*} u_{x x}^{*} x^{*} & =0 \\
\left(\lambda_{M}^{*}-\lambda_{F}^{*}\right)\left\{\eta\left(u_{x}^{*}-\phi\right) \mathcal{X}_{B}^{*}+\left(U_{c}^{*}-\alpha\right) \mathcal{C}_{B}^{*}\right\} & =\lambda_{F}^{*}\left\{\mathcal{R}_{M, g}^{*}-\mathcal{R}_{F, g}^{*}-\alpha\left(\lambda_{M}^{*}-\lambda_{F}^{*}\right)\right\} \mathcal{G}_{B}^{*},
\end{aligned}
$$

where $\lambda_{F}^{*}=\frac{v_{g}^{*}-\alpha+\mathcal{R}_{F, g}^{*}}{\alpha}$ and $\lambda_{M}^{*}=\frac{\eta\left(u_{x}^{*}-\phi\right)}{\phi\left(1+B^{*}\right)}$. See Appendix A for the derivation.

The steady state fiscal GEE (19) describes the long-run interdependence between fiscal and monetary policy. Specifically, the distortion due to monetary policy (how far $x^{*}$ is away from the first-best, $\hat{x}$, as measured by $\lambda_{M}^{*}$ ) interacts with fiscal policy distortions (how far $c^{*}$ and $g^{*}$ are away from $\hat{c}$ and $\tilde{g}_{F}$, respectively, as measured by $\lambda_{F}^{*}$ ).

As we shall see, fiscal considerations are the main driver of monetary policy in the long run. From (19) and given $\lambda_{F}^{*}=\frac{v_{g}^{*}-\alpha+\mathcal{R}_{F, g}^{*}}{\alpha}$, exogenous changes to the marginal value of public expenditure for the fiscal authority, $v_{g}+\mathcal{R}_{F, g}$, affect the steady state allocation of the daygood and hence, long-run monetary policy. In fact, under fairly weak conditions one can show that the long-run money growth rate is decreasing in the fiscal authority's benevolence. ${ }^{16}$ In other words, larger political frictions on the fiscal side would not only imply larger than socially optimal expenditure, but higher long-run inflation as well, which provides a clear motivation for wanting to reform the central bank.

The steady state monetary GEE (20) indicates how the desired level of long-run policy distortions depend on the relative benevolence of the two authorities. Under the assumption that $\mathcal{X}_{B}, \mathcal{C}_{B}, \mathcal{G}_{B}<0$, the sign of $\lambda_{M}^{*}-\lambda_{F}^{*}$ is the same as the sign of $\mathcal{R}_{M, g}^{*}-\mathcal{R}_{F, g}^{*}$. Thus, the authority that derives lower marginal utility from public expenditure will implement lower distortions. This has implications for long-run debt, as shown in the following section.

Consider now the case $\mathcal{R}_{F}(g)=\mathcal{R}_{M}(g)$, i.e., when the two government authorities have the same preferences. Then, (20) implies $\lambda_{F}^{*}=\lambda_{M}^{*}$ and the steady state can be solved locally, as it no longer depends on the derivatives of policy functions. Note that, given $\mathcal{X}_{B}^{*}<0$, small changes in debt choice at $B^{*}$ still have a direct impact on the current government budget constraint through their effects on future policy. However, the net effect of these variations is zero, i.e., the time-consistency problem cancels out at the steady state. This discussion is formalized in the following result.

Proposition 1 Assume $\mathcal{R}_{F}(g)=\mathcal{R}_{M}(g)$ and initial debt equal to $B^{*}$. Then, a government with commitment and a government without commitment will both implement the allocation $\left\{x^{*}, c^{*}, g^{*}\right\}$ and choose debt level $B^{*}$ in every period.

This proposition generalizes the result in Martin (2011), which studies the benevolent case, $\mathcal{R}_{F}(g)=\mathcal{R}_{M}(g)=0$. As long as the fiscal and monetary authorities agree on the political rent derived from public-good provision, the steady state of the MPME is constrained-efficient, and endowing the government with commitment at $B^{*}$ would not affect the allocation. Importantly, however, in the presence of political frictions, policymakers and private agents disagree on

\footnotetext{
${ }^{16}$ For example, assume that $u(x)$ is constant elasticity-of-substitution and $v_{g g}+\mathcal{R}_{F, g g}$ is close to a constant.
} 
the desired magnitude of policy distortions. By (14), the steady state allocation and debt level depend on the political rent function and thus, vary with the degree of government benevolence. This suggests the possibility that institutional reform could improve the welfare of private agents, so that implemented policy is more aligned with their preferences. What Proposition 1 shows is that this welfare improvement cannot be achieved with more commitment power.

\subsection{Effects of central bank independence}

As argued above, a less benevolent fiscal authority implies not only higher public expenditure, but also higher inflation. By Proposition 1, when both government authorities are aligned in their objectives, limited commitment is not an issue at the steady state, so it seems natural instead to consider reforming the central bank in order to curb the effects of political frictions on government policy. As stated in the introduction, a widely accepted definition of central bank independence (see Walsh, 2008) refers to independence from the pressures of politicians in the conduct of monetary policy. In the context of the model, increasing central bank independence means increasing the distance between the (marginal) political payoffs derived by the fiscal and monetary authorities. In principle, the divergence in preferences could go in either direction and still be interpreted as increased independence. However, since central bank independence is typically viewed as a desirable institutional change and to help cement some intuition, I will focus the exposition of results below by interpreting more independence as equivalent to more benevolence.

Let us first better understand how political rents affect government policy. Note that, from (14), as the value derived from public-good provision by the fiscal authority converges to a linear function, policy distortions (as measured by $\lambda_{F}$ ) converge to a constant, i.e., they become independent of the level of debt. This is a property that can be exploited to simplify the model dynamics considerably. In particular, the economy would converge to the steady state in a single period, which leads to the following characterization of the MPME.

Proposition 2 Assume $v_{g}+\mathcal{R}_{F, g} \rightarrow \psi_{F}>\alpha$. Then there exists a unique MPME and for all $B \in \Gamma: \mathcal{B}(B) \rightarrow B^{*}>-1 ; \mathcal{X}_{B}<0 ; \lambda_{F}=\lambda_{F}^{*}>0, \lambda_{M}=\lambda_{M}^{*}>0$; and the monetary GEE (18) can be rewritten as

$$
\alpha\left(1+\lambda_{M}^{*}\right)\left(\lambda_{M}^{*}-\lambda_{F}^{*}\right)=\mathcal{R}_{M, g}^{*}-\mathcal{R}_{F, g}^{*}
$$

For this case, we verify several of the working assumptions made in the preceding section; specifically, $\mathcal{X}_{B}<0, \lambda_{F}, \lambda_{M}>0$, the existence of a unique (differentiable) equilibrium and convergence to a steady state. The MPME is fully characterized in the proof of the propositionsee Appendix B.

An important implication of Proposition 2 is that altering the political influence on the central bank affects monetary policy in the short run, but has no effect on long-run monetary policy and inflation. To see this, note that, given $\lambda_{F}=\lambda_{F}^{*}=\psi_{F} / \alpha-1$, the fiscal GEE in steady state (19) implies $x^{*}$ does not depend on $\mathcal{R}_{M}(g)$. Therefore, from (6) the long-run money growth rate and thus, inflation, do not depend on $\mathcal{R}_{M}(g)$ either. In the short run, however, by (16), $x$ depends on $\lambda_{M}$; from the monetary GEE (21) and the fact that $\lambda_{M}=\lambda_{M}^{*}, x$ and therefore the money growth rate, both depend on $\mathcal{R}_{M}(g)$. This result suggests that, in more general environments, increasing central bank independence will affect monetary policy temporarily, along the transition path, with only second-order effects on long-run policy - see the analysis in Section 4. In other words, central bank independence may successfully lower inflation for a while, but would not be conducive to lower permanent inflation.

The degree of central bank independence has an impact on debt and the primary deficit. Given $\lambda_{M}^{*}=\frac{\eta\left(u_{x}^{*}-\phi\right)}{\phi\left(1+B^{*}\right)}$ and the fact that $x^{*}$ does not depend on $\mathcal{R}_{M}(g)$, the monetary GEE 
(21) implies that altering the central bank's marginal political rent affects the choice of debt. Since $\lambda_{F}$ does not depend on $\mathcal{R}_{M}(g)$, by (7) and (13), taxes and the night-good allocation are invariant to the degree of central bank independence. From the consolidated government budget constraint (11), changes in debt may affect expenditure and thus, the primary deficit. The effect in the short-run is ambiguous since monetary policy is also changing. In the long-run, however, since inflation and taxes are invariant, higher steady state debt due to higher central bank independence implies lower expenditure and thus, a lower primary deficit.

Focus now on a one-time, unanticipated increase in central bank independence. To obtain sharper policy implications, assume $\mathcal{R}_{i}(g)=\left(\omega_{i}^{-1}-1\right) g, \omega_{i} \in(0,1]$, for $i=\{F, M\}$. Thus, increasing independence means going from institutional regime $\left\{\omega_{F}, \omega_{M}\right\}$ to $\left\{\omega_{F}, \omega_{M}^{\prime}\right\}$, with $0<\omega_{M}<\omega_{M}^{\prime} \leq 1$.

Proposition 3 Assume $v_{g} \rightarrow \psi>\alpha$ and $\mathcal{R}_{i}(g)=\left(\omega_{i}^{-1}-1\right) g, \omega_{i} \in(0,1]$, for $i=\{F, M\}$. Consider an unanticipated increase in $\omega_{M}$. Then, in the short run, for any given level of debt, the money growth rate decreases, while debt choice increases. In the long run, relative to the pre-reform steady state, debt increases, the primary deficit decreases, while the money growth rate and inflation remain the same.

When a central bank becomes more independent from political influence, i.e., derives a lower marginal political rent from public-good provision, it is less willing to monetize the debt. In other words, monetary policy becomes less accommodative. The assumption on preferences in Proposition 3 implies that the distortions implemented by the fiscal authority are kept the same. Lower current seigniorage then leads to higher debt accumulation. In turn, a larger debt tomorrow triggers a higher money growth rate, in such a way that long-run monetary policy remains unaltered by the reform. On the upside, there is a permanent decrease of the primary deficit.

How does this work? By Proposition 2, $\lambda_{M}=\lambda_{M}^{*}$, with $\lambda_{M}=\frac{\eta\left(u_{x}-\phi\right)}{\phi(1+B)}$ and $\lambda_{M}^{*}=\frac{\eta\left(u_{x}^{*}-\phi\right)}{\phi\left(1+B^{*}\right)}$. Under the assumptions in Proposition 3, (21) becomes $\alpha\left(1+\lambda_{M}^{*}\right)\left(\lambda_{M}^{*}-\lambda_{F}^{*}\right)=\omega_{M}^{-1}-\omega_{F}^{-1}$. Thus, when $\omega_{M}$ increases, $\lambda_{M}^{*}$ decreases and so does $\lambda_{M}$. In other words, a more independent central bank lowers current and future distortions. Given that from (19), $x^{*}$ is fully determined by $\lambda_{F}^{*}$, which does not vary with $\omega_{M}$, for the central bank to lower current and future distortions, it must implement an increase in both $x$ and $B^{*}$. Thus, the current money growth rate decreases, while it remains invariant in the long-run, given that $x^{*}$ does not change. Current expenditure may go up or down, depending on the curvature of $u(x)$, to satisfy the consolidated government budget constraint. In the long run, a lower money growth rate and higher debt necessarily imply a smaller primary deficit.

Immediately following a reform that makes the central bank more independent, monetary policy behaves as one would expect. The idea of a more independent central bank is to reduce inflationary pressures caused by excessive spending. However, the necessary increase in debt counteracts this objective in the long run. Key to this result is the fact that the central bank finds it optimal to be more accommodative the higher the debt is. In more general environments than the one in Proposition 3 (i.e., where the transition to steady state takes more than one period), the elasticity of monetary policy to changes in debt will determine how long a low-inflation regime can be maintained, until the burden of higher debt forces accommodation. It follows then, that if monetary policy could be made fully independent of debt levels, permanently lower inflation could be achieved. 


\subsection{Inflation targeting}

A stricter implementation of central bank independence would involve endowing the monetary authority with an explicit inflation target or, equivalently, hiring a central banker that only cares about implementing a constant inflation rate. In such a case, monetary policy would be independent of the level of debt. By conditions (6) and (10), implementing a constant day and night allocation achieves a constant inflation rate through a constant money growth rate. Here, I will show that it is sufficient to characterize an inflation target in terms of a fixed day-good allocation.

Consider a central bank subject to the following rule:

$$
\omega_{T} u_{x}-\phi=0
$$

where $\omega_{T} \in(0,1]$. Clearly, when $\omega_{T}=1$, the central bank is implementing the first-best daygood allocation, $\hat{x}$, which from (6) implies $\mu=\beta-1$, i.e., the Friedman rule. When $\omega_{T} \in(0,1)$, $x<\hat{x}$ and strictly increasing in $\omega_{T}$. Assuming a constant night-good allocation (to be verified below), the inflation target - which in this case equals the money growth rate, as given by (6) and (10)-is decreasing in $\omega_{T}: \pi_{T} \equiv \beta\left(\eta / \omega_{T}+1-\eta\right)-1$. The rule specified in (22) is a commitment to a fixed inflation rate, which the fiscal authority will take as given when it implements policy every period. Since there is no aggregate uncertainty or information frictions in the environment, there is no need to consider a tolerance band around the target.

Given that the restriction (22) implies $\mathcal{X}_{B}=0$, the fiscal GEE (17) implies $\lambda_{F}-\lambda_{F}^{\prime}=0$ and thus, $B^{\prime}=B$. In other words, every level of debt is a steady state, which verifies the claim above that the night-good allocation would be constant if the day-allocation were fixed. The intuition for this result is that since monetary policy is no longer affected by the level of debt, both the time-consistency and political disagreement problems disappear, and the only remaining incentive for the fiscal authority is to (perfectly) smooth distortions over time. The fiscal authority is free to induce any level of debt consistent with its revenue and expenditure choices and satisfying the government budget constraint, but finds it optimal not to change it. Thus, once an inflation target is set, the economy remains forever at the initial debt level.

The following proposition establishes how political frictions affect fiscal policy within an inflation targeting regime.

Proposition 4 If the monetary authority sets an inflation target following (22) then the primary deficit is strictly decreasing in $\omega_{T}$ and does not depend on $\mathcal{R}_{F}(g)$.

An inflation targeting regime makes both monetary policy and the primary deficit completely independent of fiscal considerations. What it cannot address is the size of government, which is still tied to the political rent derived by the fiscal authority. Note that one can easily generalize this result to an environment with aggregate fluctuations. For a similar result to hold, monetary policy does not need to be constant and could be set as a function of the exogenous aggregate state (e.g., total factor productivity); critically, however, monetary policy needs to be independent of the level of debt.

Finally, note that an inflation target is equivalent to an interest rate peg, in the sense of Woodford (2001). Defining the nominal interest rate as $i \equiv 1 / q-1$ and using (6) and (9), a monetary authority setting an inflation target according to (22) could alternatively implement the same equilibrium by fixing an interest rate target equal to $i_{T} \equiv \eta\left(\omega_{T}^{-1}-1\right)$, which is independent of debt, fiscal policy and political frictions. 


\section{Numerical Analysis}

\subsection{Calibration}

To evaluate the effects of a reform that makes the central bank more independent, we can compare the policy functions and steady state statistics of the environments with and without central bank independence. Assuming $\mathcal{R}_{i}(g)=\left(\omega_{i}^{-1}-1\right) g$, for $i=\{F, M\}$, consider four institutional regimes: "BNV" (benevolent) corresponds to $\omega_{F}=\omega_{M}=1$ and is presented as a reference point; "PRE" (pre-reform) corresponds to an environment with political frictions and without an independent central bank, i.e., $\omega_{F}=\omega_{M}<1$; "ICB" considers the case of an independent (more benevolent) central bank, i.e., $\omega_{F}<\omega_{M} \leq 1$; and "TRG" assumes the central bank targets the inflation rate, following (22) for a given $\omega_{T}$.

The economy is calibrated to the postwar U.S., since this will allow us to interpret the model's predicted increase in debt from regimes PRE to ICB as a possible explanation for the increase in debt observed in the 1980s. The increase in debt during this period was not associated with a transitory or permanent increase in public expenditure. Hence, one possible hypothesis, as suggested by the theory, would be that the rise in debt was (at least partially) attributable to an increase in the Federal Reserve's independence from political influence. Section 4.7 explores the plausibility of this premise.

The working assumption is that $2 \%$ annual inflation is optimal. Currently, this is the desired long-run rate (implicitly) targeted by the Federal Reserve. ${ }^{17}$ The values for $\omega_{F}$ and $\omega_{M}$ are picked so that, for a given calibration for regime PRE, as described below, there is a $2 \%$ inflation in the steady state of regime BNV, and so that when switching from regime PRE to ICB, inflation drops to $2 \%$ annual on impact. For regime TRG, the value of $\omega_{T}$ is chosen so that annual inflation is $2 \%$ as well.

Consider the following functional forms: $u(x)=\frac{x^{1-\sigma}-1}{1-\sigma} ; U(c)=\frac{c^{1-\rho}-1}{1-\rho}$; and $v(g)=\ln g$. Set $\eta$ to one-half, i.e., an equal measure of consumers and producers in the day market. For a given institutional regime $\left\{\omega_{F}, \omega_{M}\right\}$, the parameters left to calibrate are $\alpha, \beta, \rho, \sigma$ and $\phi$.

Government in the model corresponds to the federal government, where monetary policy is conducted by the Federal Reserve. Period length is set to a fiscal year. The variables targeted in the calibration are: debt over GDP, inflation, nominal interest rate, outlays (excluding interest) over GDP and revenues over GDP. All variables are taken from the Congressional Budget Office. Government debt is defined as debt held by the public, excluding holdings by the Federal Reserve system. Inflation is measured using the GDP deflator, which over the period considered provides statistics similar to the PCE (personal consumption expenditures) deflator.

We need to specify the model steady state statistics that correspond to the selected calibration targets. Define nominal GDP as the sum of nominal output in the day and night markets. Let $Y$ be nominal GDP normalized by the aggregate money stock, i.e., $Y \equiv p_{x}(\eta x)+p_{c}(c+g)$. From the equilibrium conditions derived in Section 2.2 we have $p_{x}=\frac{1}{x}$ and $p_{c}=\frac{U_{c}}{\phi x}$. Thus, $Y=\eta+\frac{U_{c}(c+g)}{\phi x}$.

For debt over GDP use $\frac{B(1+\mu)}{Y}$, since debt is measured at the end of the period in the data. From (6) and (10), inflation equals money growth in steady state, i.e., $\pi=\mu$. Interest payments over GDP are defined as $\frac{B(1+\mu)(1-q)}{Y}$, which provides a formula to derive the annual nominal interest rate, $i \equiv \frac{1}{q}-1$, using data on debt and interest payments. Outlays and revenues are defined as $\frac{p_{c} g}{Y}$ and $\frac{p_{c} \tau n}{Y}$, respectively, where $n=c+g$ from the night-resource constraint.

\footnotetext{
${ }^{17}$ This target is explicitly mentioned in several official statements and speeches. For example, see the "Statement on Longer-Run Goals and Monetary Policy Strategy" from January 29, 2013.
} 
Parameters are chosen so that the steady state of regime PRE matches the calibration targets described above, except debt over GDP, for 1955-2008 (see Table 3 below). The theoretical results stated that making a central bank more independent would imply an increase in debt, with no significant variations in long-run inflation. Thus, debt in regime PRE is targeted for the sub-period 1970-1979, which precedes the largest peacetime debt expansion until the recent recession, as described above and further discussed in Section 4.7. Tables 1 and 2 present the parameterization used in the numerical analysis.

Table 1: Institutional Regimes

\begin{tabular}{|l|c|c|c|}
\hline Regime & $\omega_{F}$ & $\omega_{M}$ & $\omega_{T}$ \\
\hline BNV & 1.0000 & 1.0000 & - \\
PRE & 0.3304 & 0.3304 & - \\
ICB & 0.3304 & 0.9222 & - \\
TRG & 0.3304 & - & 0.9049 \\
\hline
\end{tabular}

Table 2: Benchmark Calibration

\begin{tabular}{|c|c|c|c|c|c|}
\hline$\alpha$ & $\beta$ & $\eta$ & $\rho$ & $\sigma$ & $\phi$ \\
\hline 7.5370 & 0.9691 & 0.5000 & 6.4045 & 3.8745 & 2.0389 \\
\hline
\end{tabular}

I solve the MPME for each institutional regime globally using a standard projection method. ${ }^{18}$ The numerical algorithm solves for $\{\mathcal{B}, \mathcal{X}, \mathcal{C}, \mathcal{G}\}$ that satisfy (11), (13), (17) and (18) for all $B \in \Gamma$. The set $\Gamma$ is discretized over 10 gridpoints. I use cubic splines to interpolate between gridpoints and to evaluate the derivatives of policy functions. There are various ways to measure the precision of the solution. Here, I take the total derivative of the government budget constraint (11) with respect to $B$, which in an MPME is equal to zero for all $B \in \Gamma$. The sum of squared residuals of the derivative of the government budget constraint, evaluated at 1,000 points in $\Gamma$ is equal to $6 e^{-9}$ for regimes BNV, PRE and ICB; for case TRG the sum of squared residuals equals $5 e^{-15}$. Note that the steady states of regimes BNV, PRE and TRG can be solved locally since they do not depend on the derivatives of policy functions; for these cases, we can compare the steady states obtained using local and global methods to further verify the precision of the global solution.

\subsection{Effects of central bank independence}

Figure 1 compares inflation and the primary deficit under regimes PRE and ICB. The black markers indicate the steady state of the respective regime. In both cases, equilibrium inflation is increasing in debt, as established in the theoretical section, while the primary deficit is decreasing in debt. A reform that increases the independence of the central bank from political frictions implies lower inflation and lower taxes, for any given level of debt. On impact, inflation decreases and the primary deficit increases. Over time, as deficits accumulate, debt and inflation increase.

Figure 2 adds regime TRG, where inflation is fixed to the target, regardless of the level of debt. This policy removes the incentives to monetize debt beyond a pre-committed rate. As a result, debt stays constant and the primary deficit adjusts to account for the implied variations

\footnotetext{
${ }^{18}$ See Martin $(2009,2013)$ for a description.
} 
Figure 1: Policy Effects of Central Bank Independence
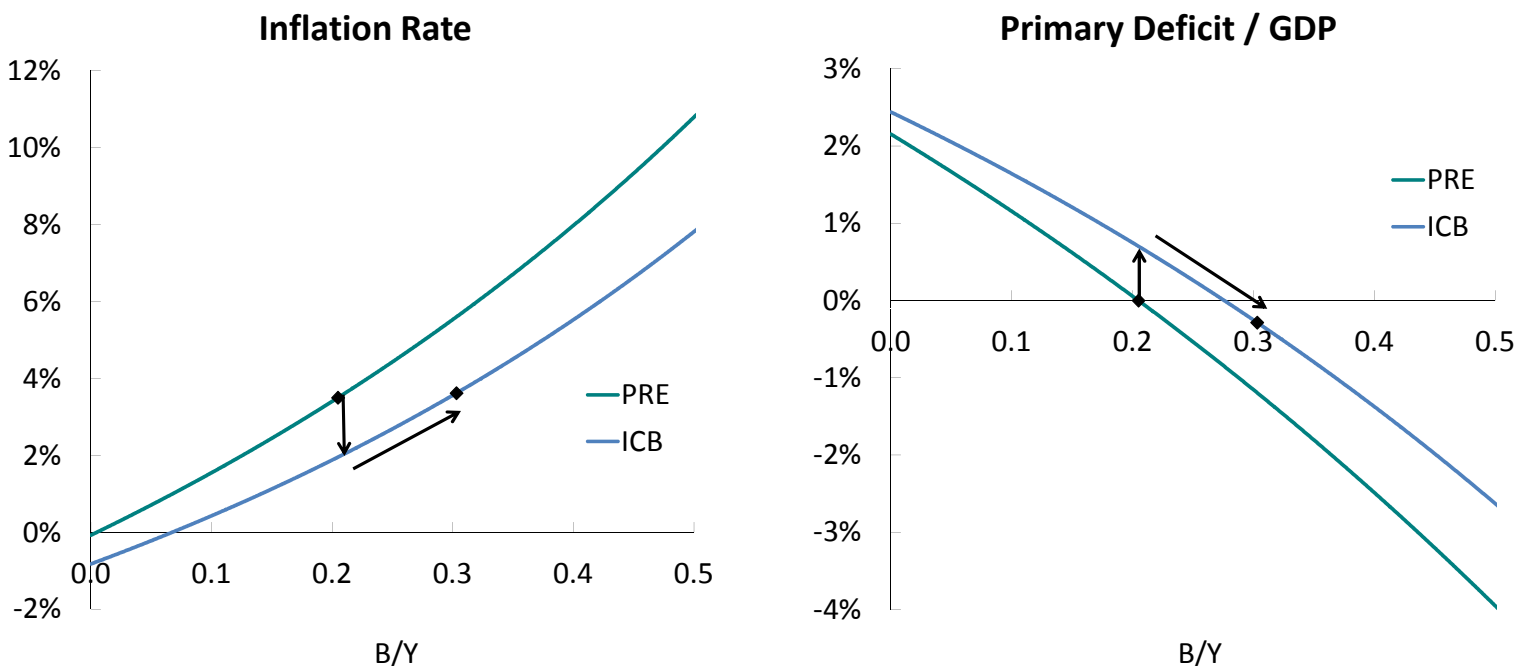

in seigniorage revenue. When going from PRE to TRG, inflation drops immediately to the target and the fiscal authority starts running a primary surplus.

Table 3 presents the steady state statistics for all four institutional regimes. As we can see, the differences in inflation between the cases with and without an independent central bank virtually vanish in the long run, generalizing the results from Propositions 2 and 3. In effect, the only sizable difference between these two cases is debt over GDP, which increases substantially post-reform, going from $21.2 \%$ to $31.4 \%$. Consistent with the theoretical results, the primary deficit is lower under an independent central bank. For the calibrated economies we go from a zero primary deficit in regime PRE to a $0.3 \%$ of GDP surplus in regime ICB.

How important is the policy response of the fiscal authority to explain the effects of institutional reform? To answer this question consider the following experiment. Suppose that when switching from regime PRE to ICB we do not allow the fiscal authority to re-optimize.

Figure 2: Policy Effects of Inflation Targeting
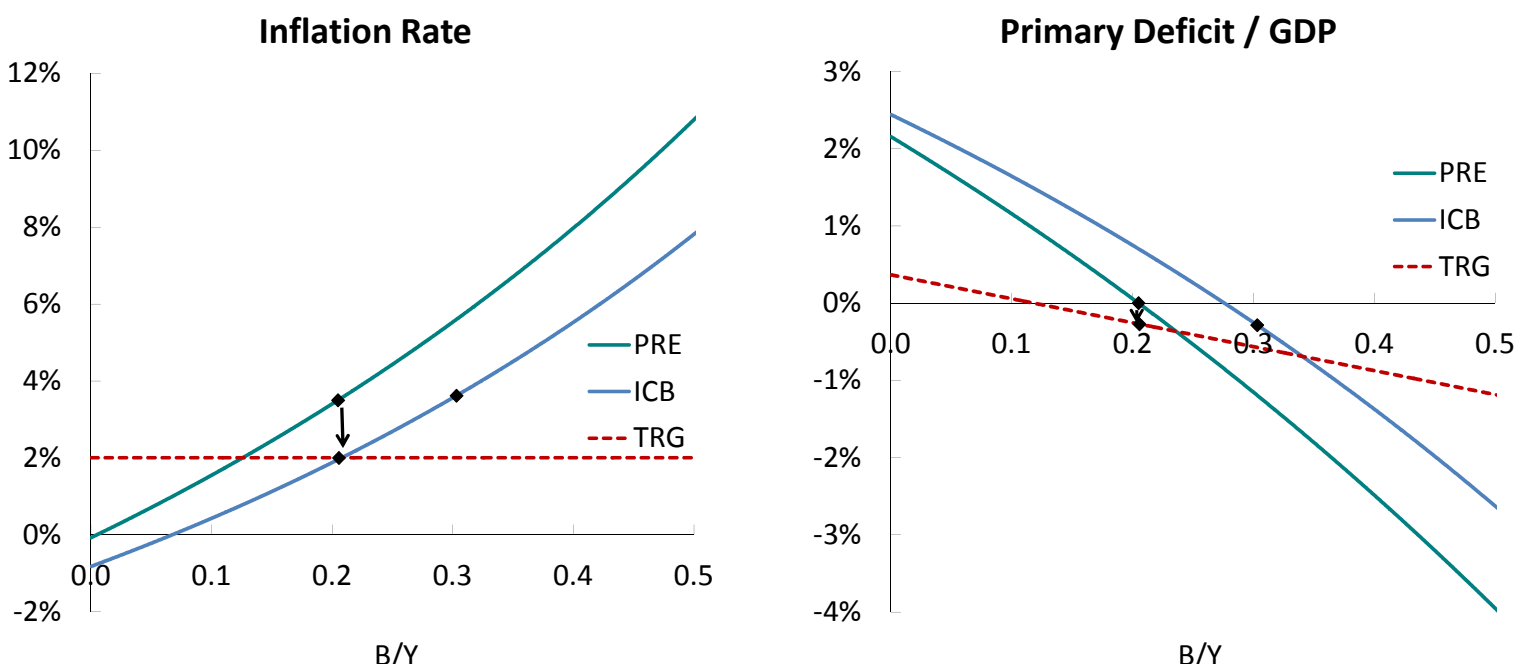
Table 3: Steady state statistics

\begin{tabular}{|l|c|c|c|c|}
\hline & BNV & PRE & ICB & TRG \\
\hline$\frac{B(1+\mu)}{Y}$ & 0.220 & 0.212 & 0.314 & 0.210 \\
$\pi$ & 0.020 & 0.035 & 0.036 & 0.020 \\
$i$ & 0.053 & 0.068 & 0.069 & 0.053 \\
$\frac{p \tau n}{Y}$ & 0.142 & 0.180 & 0.183 & 0.183 \\
$\frac{p g}{Y}$ & 0.139 & 0.180 & 0.180 & 0.180 \\
\hline
\end{tabular}

In this case, the equilibrium inflation rate of Figure 1 would look nearly identical to the case ICB, while the primary deficit function would look almost identical to the case PRE. In the long-run, debt over GDP would increase from $21.2 \%$ to $23.8 \%$ and annual inflation would drop from $3.5 \%$ to $2.3 \%$ (the primary surplus would be $0.3 \%$ of GDP as in regime ICB). The increase in debt is only driven by the loss in seignorage and not by the strategic interaction between the two government authorities. The lack of response in the primary deficit function implies the increase in debt would be severely mitigated, which also explains why inflation would not increase back up as much as in regime ICB. In all, accounting for how the fiscal authority responds to institutional reform is critical for our proper understanding of its effects.

A key parameter that was not calibrated is the curvature of $v(g)$. So, one may ask whether this had any effects on the results. Varying the curvature of $v(g)$ changes the steepness of the inflation function. Specifically, flatter valuations of public-good provision imply inflation responds less to changes in debt, as in the theoretical analysis of the previous section, when $v(g)$ was assumed to be linear. In the long run, increasing the curvature of $v(g)$ mitigates the variations in steady state statistics of increasing central bank independence, while decreasing the curvature exacerbates them. However, regardless of these variations, the changes in long-run inflation are always second-order.

The last column in Table 3 shows that when the central bank is endowed with an explicit policy target, inflation is lowered permanently, with no further significant changes. As argued above, the critical difference between the cases ICB and TRG is that in the latter, monetary policy does not depend on the level of debt. With a target that lowers inflation, the primary deficit decreases as well.

\subsection{Welfare}

Having analyzed the policy implications of making the central bank more independent, it is natural to wonder about the welfare properties of such a reform. To evaluate welfare, I will measure the one-time fee that an agent would be willing to pay, in consumption terms, to switch from the steady state of a MPME with $\omega_{F}=\omega_{M}$ to an alternative institutional regime. Let

$$
\Upsilon(\Delta, \omega) \equiv \eta\left(u\left(x^{*}(1+\Delta)\right)-\phi x^{*}\right)+U\left(c^{*}(1+\Delta)\right)+v\left(g^{*}\right)-\alpha\left(c^{*}+g^{*}\right)+\beta V\left(B^{*} ; \omega, \omega\right),
$$

where $\left\{B^{*}, x^{*}, c^{*}, g^{*}\right\}$ is the steady state in a MPME with $\omega_{F}=\omega_{M}=\omega \in(0,1]$ and $V\left(B ; \omega_{F}, \omega_{M}\right)$ is the agent's value function (at the beginning of the day) for any given institutional regime $\left\{\omega_{F}, \omega_{M}\right\}$.

Figure 3 evaluates the welfare properties of central bank independence. Specifically, it measures $\Delta_{M}$ solving $\Upsilon\left(\Delta_{M}, \omega_{F}\right)=V\left(B^{*} ; \omega_{F}, \omega_{M}\right)$. The figure displays $\Delta_{M}$ as a function of $\omega_{M}$, for a given $\omega_{F}$.

From an initial arrangement $\omega_{F}=\omega_{M}$, making the central bank more independent (increas- 
Figure 3: Welfare Effects of Central Bank Independence

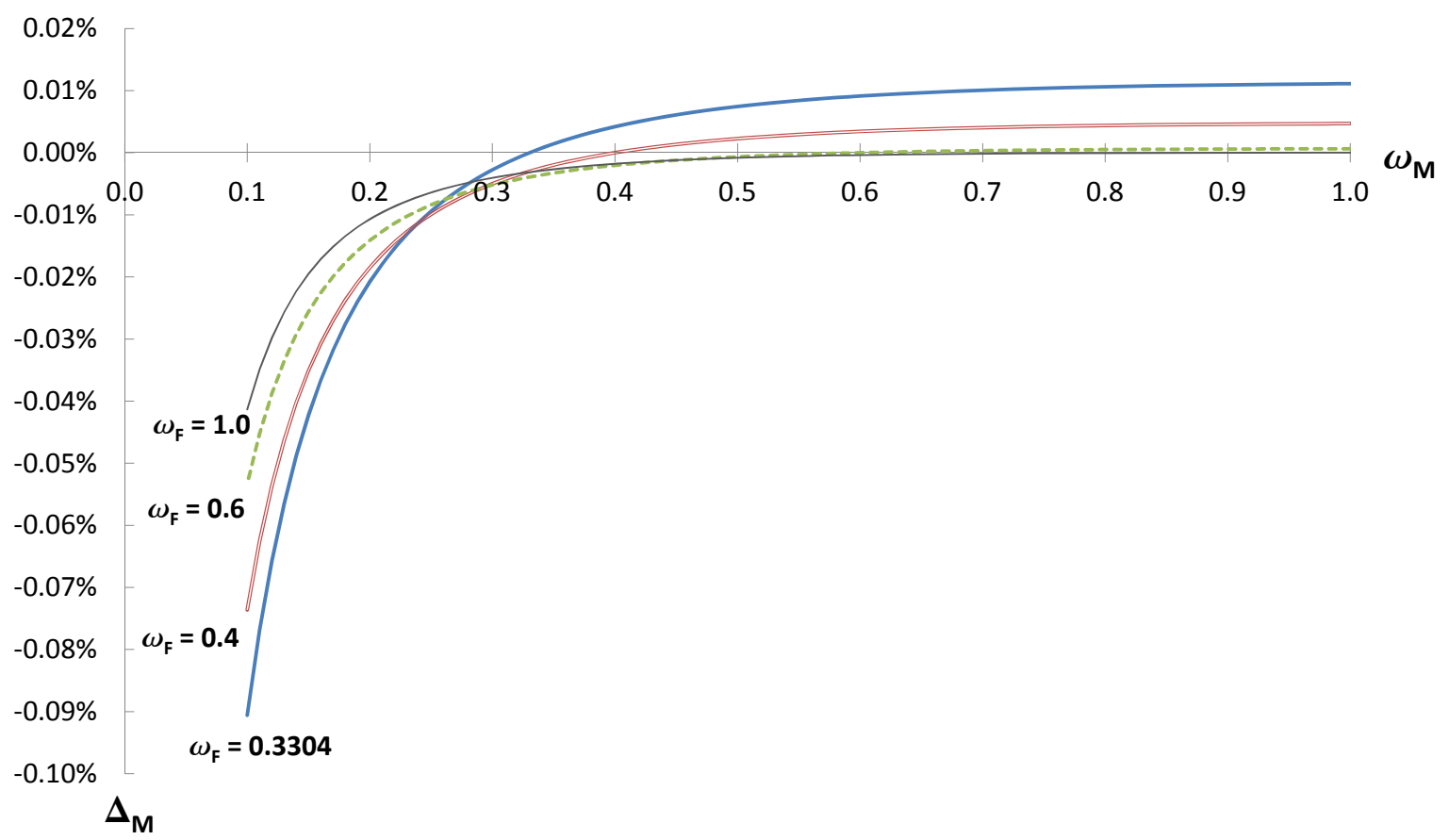

ing $\left.\omega_{M}\right)$ improves welfare. The welfare gain for the benchmark case is worth about $0.01 \%$ of consumption. The improvement is higher the less benevolent the government is initially and the more benevolent the monetary authority becomes. Steady state welfare is actually lower in ICB than PRE. Thus, all the welfare gains come from the transition, a period of temporarily lower inflation and higher deficits, as analyzed further below.

The gains from the central bank becoming fully benevolent are tiny; most of the welfare effects occur for relatively low increases in benevolence, irrespective of the fiscal authority's own benevolence. In this respect, consider the risks of having a central bank that derives high political rents. As Figure 3 shows, making the central bank less benevolent than the fiscal authority carries a welfare cost, which can become sizable as we lower $\omega_{M}$. This last result contrasts sharply with the prescription derived from environments where a central bank, instead of playing a game against a fiscal authority, faces labor unions that bargain over wages. For example, Cukierman and Lippi (1999) argue that when the number of unions is small (i.e., wage bargaining is centralized), it is optimal to delegate monetary policy to a central banker that cares about inflation less than society. Here, instead, it is always optimal to have a more benevolent central bank.

\subsection{Optimal inflation target}

Figure 4 shows the welfare properties of inflation targeting, relative to an economy with no central bank independence. From Section 3.7 we know that if we switch to an inflation target, debt will remain unchanged at the initial level. Let $\left\{x_{T}(B), c_{T}(B), g_{T}(B)\right\}$ be the allocation for a given target rule $\omega_{T}$ and initial debt level $B$. Let $V\left(B ; \omega_{F}, \omega_{T}\right)$ be the ex-ante net present value for an agent living in an inflation targeting economy. We can now calculate the onetime fee that agents would be willing to pay to switch from the MPME with $\omega_{F}=\omega_{M}$ to the inflation targeting regime, expressed in terms of period-consumption. That is, $\Delta_{T}$ solving $\Upsilon\left(\Delta_{T}, \omega_{F}\right)=V\left(B^{*} ; \omega_{F}, \omega_{T}\right)$. Figure 4 displays $\Delta_{T}$ as a function of the implied inflation target, $\pi_{T} \equiv \beta\left(\eta / \omega_{T}+1-\eta\right)-1$, for a given $\omega_{F}$. 
Figure 4: Optimality of Inflation Targeting

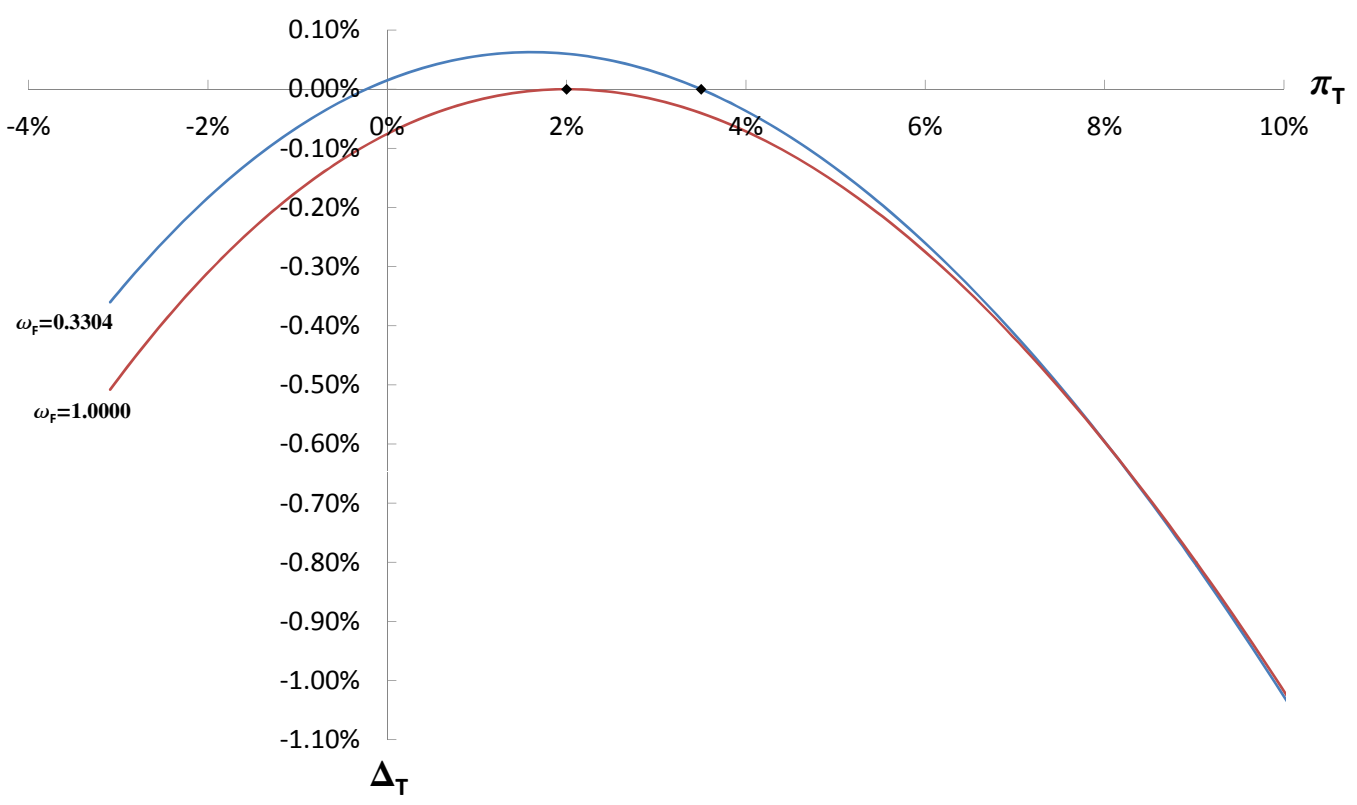

Note: Diamond markers indicate the steady state of the MPME when $\omega_{F}=\omega_{M}$.

Recall that, from Proposition 1, at the steady state of a MPME with $\omega_{F}=\omega_{M}$, a reform that endows the government with commitment has no effect on policy and therefore, no effect on welfare. Thus, for the case of a benevolent fiscal authority, $\omega_{F}=1$, the optimal inflation target coincides with the steady state inflation in the MPME when $\omega_{F}=\omega_{M}=1$. However, when $\omega_{F}<1$, an inflation target can potentially improve welfare since lower inflation may mitigate the costs of the fiscal authority's expenditure bias. For the calibrated case PRE, $\omega_{F}=0.3304$, Figure 4 shows that there is a non-trivial range of inflation targets which improve welfare over the MPME. The optimal inflation target is about $1.6 \%$ annual, which is below the inflation rate obtained in the fully benevolent case, $\omega_{F}=\omega_{M}=1$ - see Table 3 . The welfare gain associated with moving to the optimal inflation target is worth about $0.06 \%$ of consumption, which is (much) larger than the gain from switching to regime ICB.

Since there are no transitions, it is easy to decompose how an inflation target affects welfare. When going from the MPME with $\omega_{F}=\omega_{M}$ to a regime that targets a lower inflation rate, we get the following effects. First, there is an increase in day-good consumption due to lower inflation. Second, to balance the budget, taxes increase, which implies lower night-good consumption, and public expenditure decreases. Although night-labor is also lower, the overall effect implies lower utility, since fiscal distortions increase. Thus, an inflation target trades-off higher welfare in the day with lower welfare at night.

Targeting the Friedman rule - contracting the money supply at the discount rate so that the nominal interest rate is zero- lowers welfare relative to the MPME. This result should not come as a surprise, given that even a Ramsey planner would not implement the Friedman rule for any $B \in \Gamma$-see Proposition 1 and Martin (2011) for further discussion. Relative to the optimal inflation target, implementing the Friedman rule when $\omega_{F}=0.3304$ would imply a welfare loss of about $0.36 \%$ of consumption.

The welfare loss of going to the Friedman rule is largest when the fiscal authority is benevolent. If we start with a fully benevolent government, going to a central bank that targets the 
Friedman rule involves a loss of $0.51 \%$ of consumption. As a reference, going instead to a central bank with $\omega_{M}=0.3304$ (as in the benchmark, but keeping $\omega_{F}=1$ ) involves a loss of $0.003 \%$, two orders of magnitude smaller.

As we raise the inflation target, variations in welfare are increasingly dominated by the pure cost of inflation. For example, the welfare loss of going from the MPME with $\omega_{F}=\omega_{M}$ to a $10 \%$ annual inflation target is about $1 \%$ of consumption, for both cases displayed in Figure 4, which is in line with previous estimates in the literature. ${ }^{19}$ This loss increases quickly as we enter moderate-to-high inflation regimes. For example, going to $20 \%$ inflation involves a $4 \%$ loss and going to $40 \%$ inflation involves an $11 \%$ loss.

\subsection{Transitions: sudden, gradual and anticipated reforms}

Thus far, the focus has been on institutional reforms that are sudden and unexpected. In practice, however, reforms may be announced well in advance and/or implemented gradually. The long-run properties of the economies considered here are not affected by how reforms are implemented. Transitions, on the other hand, may be quite different.

Figure 5 displays the evolution of debt, the money growth rate and the primary deficit under different assumptions on how central bank independence is implemented. The starting point is the steady state of regime PRE, as defined above - see Table 3. The benchmark transition, against which all others are compared, is a sudden and unexpected shift to regime ICB in $t=0$. In this case, debt over GDP increases monotonically towards its new steady state value. Most of the debt increase occurs shortly after the reform; e.g., in the first decade, debt over GDP rises by almost 7 percentage points, roughly two-thirds of the total increase between steady states. By contrast, the money growth rate drops sharply on impact, from $3.5 \%$ to $1.9 \%$, and then slowly increases as debt is accumulated. It takes about two and half decades for money growth and inflation to surpass their pre-reform levels. Hence, even though the effects on inflation of a more independent central bank vanish in the long run, inflation remains low for an extended period, which may lead to incorrect inferences on the permanent effects of the reform. In terms of fiscal policy, the post-reform economy experiences a little over a decade of primary deficits, followed by a persistent surplus.

Consider now the effects of increasing central bank independence gradually, a case labeled "GRD" in the top panels of Figure 5. Specifically, starting in $t=0, \omega_{M}$ increases proportionally each period, until reaching 0.9222 in $t=10$. Except for the initial reform in $t=0$, the path for $\omega_{M}$ is perfectly anticipated by all agents in the economy. A gradual increase in central bank independence leads to smoother variations in debt, inflation and the primary deficit. Policy differences between regimes ICB and GRD are significant in the first decade after the initial reform and become minor after that, virtually vanishing by the third decade.

The next exercise is to consider a sudden, but anticipated increase in central bank independence. This case, labeled "ANT" in the middle panels of Figure 5, consists of an announcement in $t=-10$ that $\omega_{M}$ will permanently increase to 0.9222 in $t=0$. Thus, the difference between this case and the benchmark ICB, is that now, all private and public agents anticipate for a decade that the central bank will become suddenly more independent. The anticipation of reform induces an early reaction of fiscal and monetary policies, as both authorities internalize the future change in regime.

The last case considered, labeled "GTR", is similar to GRD, only now, at $t=0$ the central bank switches to an inflation targeting regime that gradually reaches the $2 \%$ annual inflation

\footnotetext{
${ }^{19}$ For example, see Lucas (2000) and the computations in Lagos and Wright (2005) when buyers have all the bargaining power.
} 
Figure 5: Transitions
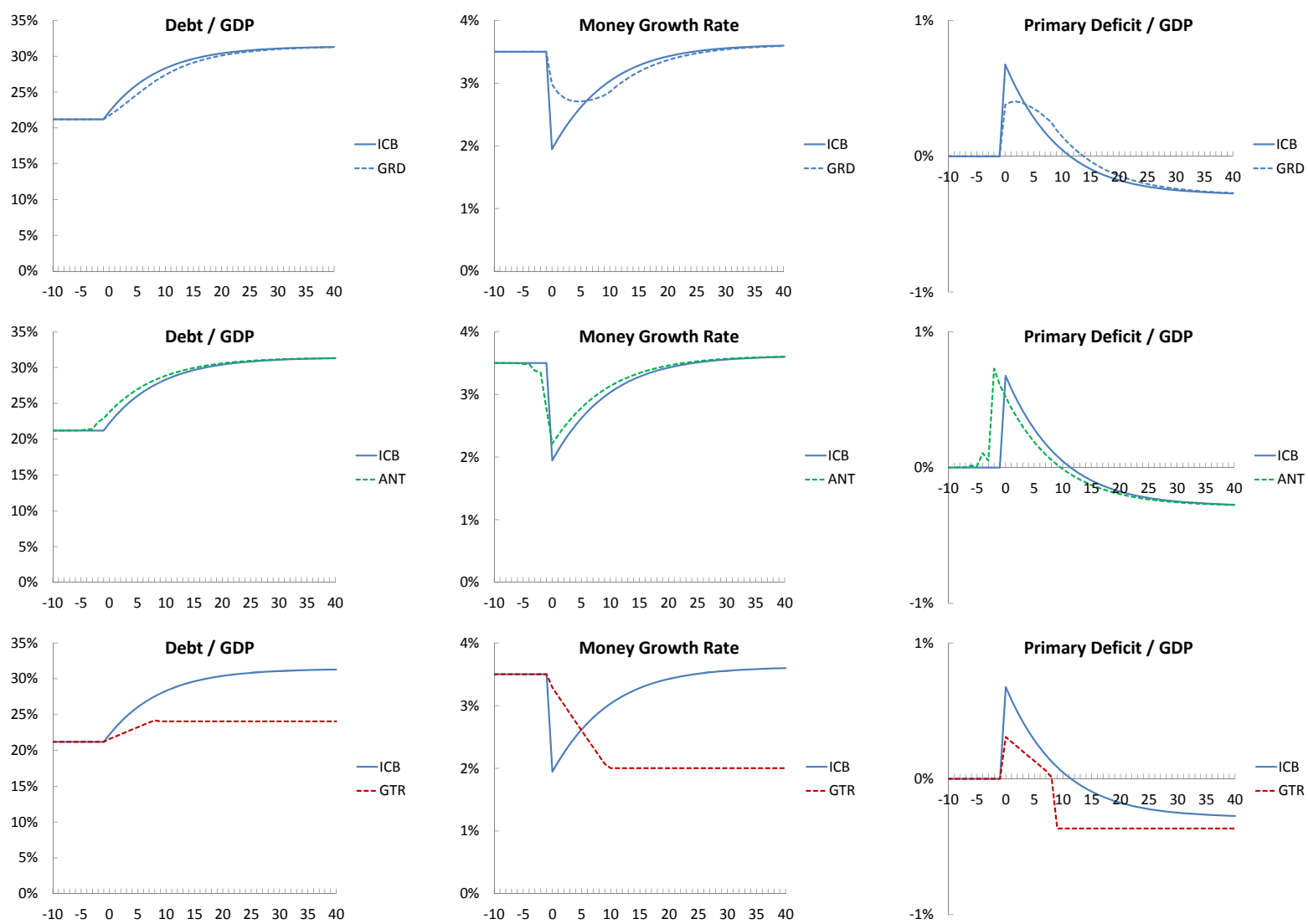

Note: economy starts at the steady state of regime PRE, with $\omega_{F}=\omega_{M}=0.3304 ;$ ICB: at $t=0, \omega_{M}$ increases to 0.9222; GRD: from $t=0$ to $t=10, \omega_{M}$ increases proportionally every year up to 0.9222; ANT: at $t=-10, \omega_{M}$ is announced to increase to 0.9222 in $t=0 ; G T R$ : at $t=0$, an inflation targeting regime is implemented which reduces inflation gradually from the previous steady state to $2 \%$ annual in $t=10$.

objective in $t=10$. In this case, debt and the primary deficit increase moderately along the transition path. Inflation drops gradually towards the $2 \%$ target.

\subsection{Empirical literature and interpretation of results}

There is a large empirical literature that has studied the cross-country relationship between long-run inflation and measures of central bank independence. Early work, such as Alesina and Summers (1993), suggests a negative correlation in developed countries. ${ }^{20}$ This has led to the view, popular among central bankers, that independence is conducive to lower permanent inflation - see Waller (2011) for a recent take. There is also some work that has questioned these findings or their interpretation. Most notably, Campillo and Miron (1997) find that after controlling for other factors that may determine inflation, central bank independence is relatively unimportant for average inflation rates. Posen (1993) suggests that low inflation and central bank independence are both caused by a strong demand for the former, and further argues that increasing central bank independence will not itself lead to lower inflation. Brumm (2011) finds that inflation and central bank independence are both endogenously determined, although still negatively correlated. Acemoglu et al. (2008) argue that the effectiveness of central

\footnotetext{
${ }^{20}$ Brumm (2006) extends this result to developing countries. See Cukierman (2008) for a survey.
} 
bank reform depends on the strength of the constrains faced by politicians and the structure of political institutions; in particular, reform is more effective in reducing inflation in societies with intermediate constraints.

A general lesson from the analysis in Section 4 is that increasing central bank independence indeed lowers inflation persistently, even if the effect vanishes in the long run due to the pressure of increased debt. An observer looking at an economy shortly after a reform may draw an incorrect inference of its lasting effects. The standard exercise of regressing average inflation against some measure of central bank independence is subject to this critique. Unless the sample period is long enough, the regression is bound to pick up the transitional rather than the permanent effects.

The theory presented in this paper is consistent with finding lower inflation after the political independence of a central bank has been increased. However, the theory does not support the hypothesis that, everything else equal, a country with a more independent central bank will register lower inflation. Unless monetary policy is conducted effectively independent of the level of debt (as in a strict inflation targeting regime) fiscal considerations dominate in the long run. On the other hand, arguments such as the ones made by Posen (1993), in which a decrease in agents' tolerance for inflation leads to lower permanent inflation, can easily be accommodated. For example, a small increase in the curvature of the night-good utility function, $U(c)$ implies a significant drop in steady state inflation, with only minor effects on fiscal policy. ${ }^{21}$

\subsection{Case study: postwar U.S.}

Arguably, the perceived independence of the Federal Reserve from other political bodies is now significantly higher than three or four decades ago. For example, Abrams (2006) discusses how President Nixon successfully pressured Fed Chairman Arthur Burns to run expansionary monetary policy. Although such degree of meddling would not be completely inconceivable today, it would likely be received with great surprise by the general public and severely dent the Fed's reputation.

The 1960s and 1970s were characterized by poor macroeconomic performance and high inflation. Explanations for this episode - dubbed the "Great Inflation" - abound. ${ }^{22}$ There is also a widespread notion that high inflation (not just in the U.S., but around the world) motivated central bank reform, which then led to lower inflation - see Walsh (2008). On the other hand, Posen (1993) argues that the inflation performance of the 1970s may have created a demand for both lower long-run inflation and increased central bank independence, while Meltzer (2009a) suggests that the end of the 1970s inflation in the U.S. was mainly due to a change in public attitudes about inflation.

The successful overturn of the Great Inflation was followed by the largest increase in U.S. public debt during peacetime - at least until the latest financial crisis and recession. What makes this increase in debt particularly puzzling is that it was not associated with a temporary (or even permanent) rise in public expenditure. There are two pertinent political events during this period which suggest a connection between institutional reform and the aforementioned policy developments. ${ }^{23}$ First, the amendment to the Federal Reserve Act in 1977 introduced what is

\footnotetext{
${ }^{21}$ Suppose we increase $\rho$ by $20 \%$ from its benchmark value to 7.6854 . Steady state annual inflation drops to $2.1 \%$ and $2.2 \%$ for regimes PRE and ICB - about a $40 \%$ reduction. In both cases, steady state debt over GDP drops by less than two percentage points and steady state expenditure over GDP drops by less than one percentage point.

${ }^{22}$ Primiceri (2006) provides an overview of competing theories and proposes his own, based on the evolution of policymakers' beliefs about natural rate of unemployment and the persistence of inflation in the Phillips curve, which fits several stylized facts on inflation and unemployment.

${ }^{23}$ Just like there are many theories for the Great Inflation, some alternative explanations have been proposed
} 
Figure 6: Number of Meetings at the White House and Official Phone Conversations Between the U.S. President and Fed Chairman

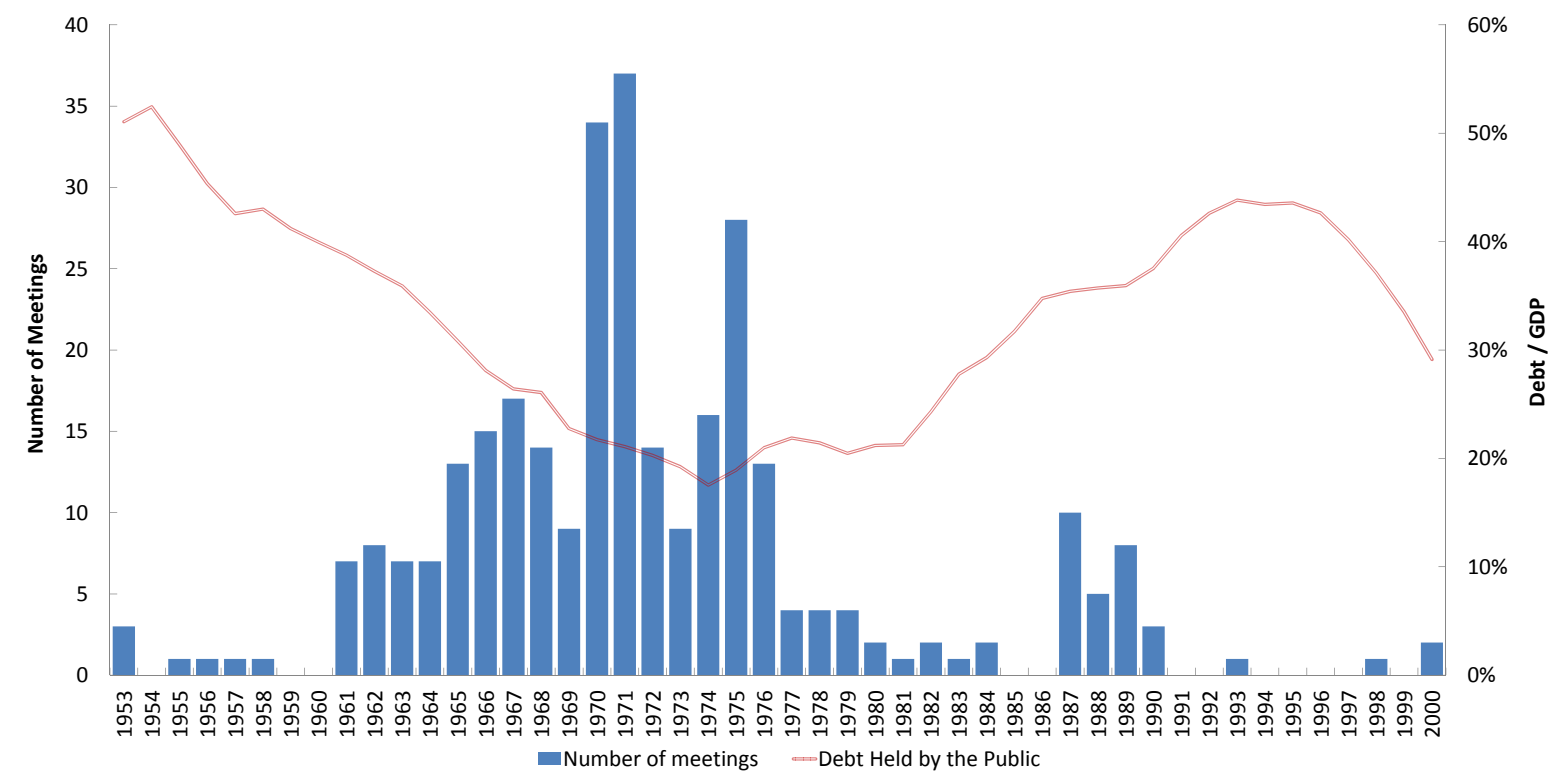

known as the "dual mandate", which states explicitly, albeit vaguely, the goals of monetary policy. Second, the appointment of Paul Volcker as Fed Chairman in 1979 arguably triggered a regime change in the conduct of monetary policy - see Benati and Goodhart (2011). Meltzer $(2009 b)$ remarks that for the whole postwar period, only part of Volcker's tenure "comes close to the textbook vision of independence".

In light of the results presented in previous sections, an explanation presents itself: the high inflation of the 1960s and 1970s, perhaps in part motivated by increased political pressures, triggered a demand for increased central bank independence, whose lasting implication was an increase in debt. What we need now is evidence of variations in Fed independence throughout this period. To this effect, I proxy central bank independence by the number of meetings between the U.S. President and the Fed Chairman. This information is available (up to the year 2000) from the daily agenda of the President, which can be obtained from the corresponding presidential library. Included are individual and group meetings at the White House, as well as official phone conversations. Figure 6 shows that these meetings were quite frequent in the 1960s and 1970s and rather infrequent in other periods. For example, presidents Kennedy, Johnson, Nixon and Ford (1961-1977) met in total about five times as much as the next four presidents. Johnson and Nixon get the lion's share of meetings, which confirms the view in Meltzer (2009a) that these two presidents interfered the most. Consistent with the theory presented here, when political interference abruptly decreased with the advent of Volcker to the Fed, there was a significant increase in public debt.

The measured variations in political interference suggest a simple exercise in the spirit of the transitions computed in Section 4.5. Suppose the central bank was independent $\left(\omega_{M}=0.9222\right)$ during the 1950s, a evidenced in Figure 6 . Then, consider a gradual decrease in independence during the 1960s (towards $\omega_{M}=0.3304$ ), followed by a decade (the 1970s) of low independence.

for the increase in debt. See Persson and Tabellini (1998) for a survey from a political economy perspective. See also Azzimonti et al. (2011) for a recent alternative take which focuses on the role of international financial markets liberalization. 
Figure 7: Effects of variations in central bank independence
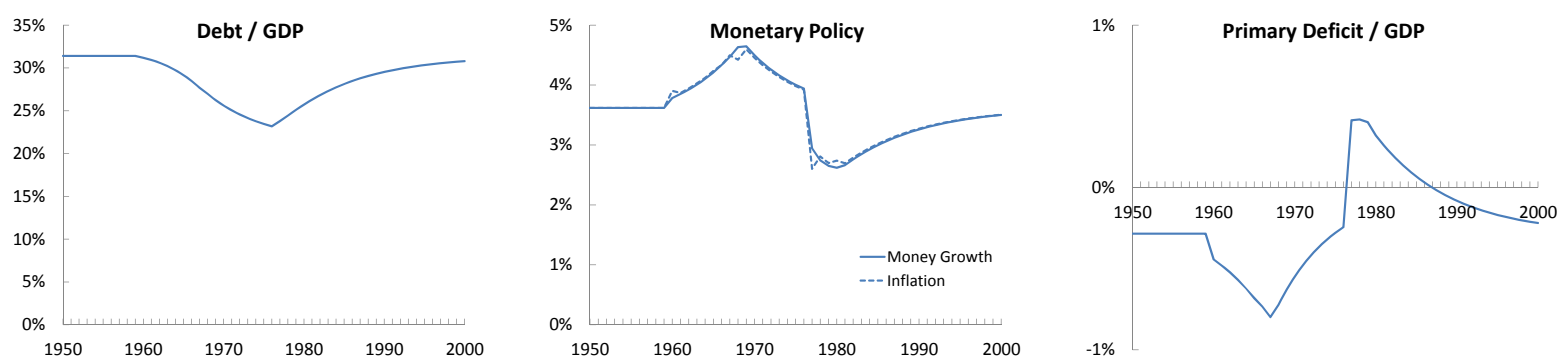

Note: the economy starts in 1950 at the steady state of regime $I C B$, with $\omega_{F}=0.3304$ and $\omega_{M}=0.9222 ;$ from 1960 to 1969, $\omega_{M}$ decreases proportionally every year up to 0.3304 and remains constant until 1976; in 1977, $\omega_{M}$ increases proportionally every year back up to 0.9222 in 1981 and remains constant after that; institutional changes in 1960 and 1977 are unanticipated.

Finally, consistent with Figure 6, assume a gradual increase in independence (again, towards $\left.\omega_{M}=0.9222\right)$ during Jimmy Carter's presidency (1977-1980), which included both the amendment to the Federal Reserve Act and the appointment of Paul Volcker as Fed chairman. The institutional changes in 1960 and 1977 are unanticipated. Figure 7 tracks the effects of these variations on debt, inflation and the primary deficit.

Although the exercise abstracts from several key economic and political events of this period - among others, the ongoing repayment of debt accumulated during World War II, the Korean War, the oil shocks of 1973 and 1979, and the defense build-up of the 1980s - it is nevertheless informative. First and foremost, even without any real shocks and in the absence of a Phillips curve policy trade-off, increased political interference in the conduct of monetary policy may have contributed by itself to higher inflation. Without any further institutional changes, this effect would have been persistent, but ultimately transitory, as long-run inflation would not be significantly altered by the degree of independence - see Section 4.5. Second, the subsequent increase in central bank independence could help explain the sharp drop in inflation and the permanent increase in debt. Third, the low levels of public debt reached during 1970s may also be explained, in part, by decreased Fed independence. From a historical perspective, debt over GDP reached $17.5 \%$ in 1974, the second lowest level in the period extending from the end of World War I until the present (the lowest point being $16.3 \%$ in 1929, when government expenditure was an order of magnitude smaller) and substantially below the levels attained in the decade leading up to World War II (about 39.5\%).

\section{Concluding remarks}

It is perhaps not surprising that increased central bank independence would lead to a less accommodative monetary policy and, at least in the short run, to lower inflation. After all, protecting an institution from political frictions necessarily implies a lower tolerance to the inefficiencies they create. Less obvious is the result that fiscal considerations dictate long-run monetary policy, even though there is limited commitment and no agency dominates the other (in the sense of Sargent and Wallace, 1981).

A general lesson is that increasing central bank independence should involve sheltering the monetary authority from both direct political pressures and from indirect influence through endogenous states of the world, such as the level of public debt. In this regard, the theory offers 
a rationale for why it would be preferable to design a central bank that is subjected to single mandates (e.g., the European Central Bank), rather than multiple objectives, some of which may be more heavily influenced by fiscal policy (e.g., the Fed's dual mandate on price stability and high employment). 


\section{References}

Abrams, B. A. (2006), 'How Richard Nixon pressured Arthur Burns: Evidence from the Nixon tapes', The Journal of Economic Perspectives 20(4), 177-188.

Acemoglu, D., Johnson, S., Querubín, P. and Robinson, J. A. (2008), 'When does policy reform work? The case of central bank independence', Brookings Papers on Economic Activity 39(1), 351-429.

Adam, K. and Bili, R. M. (2008), 'Monetary conservatism and fiscal policy', Journal of Monetary Economics 55(8), 1376-1388.

Alesina, A. and Summers, L. H. (1993), 'Central Bank independence and macroeconomic performance: Some comparative evidence', Journal of Money, Credit and Banking 25(2), 151-162.

Alesina, A. and Tabellini, G. (1987), 'Rules and discretion with noncoordinated monetary and fiscal policies', Economic Inquiry 25(4), 619-630.

Aruoba, S. B. and Chugh, S. K. (2010), 'Optimal fiscal and monetary policy when money is essential', Journal of Economic Theory 145(5), 1618-1647.

Azzimonti, M., de Francisco, E. and Quadrini, V. (2011), Financial globalization and the raising of public debt. Working Paper.

Azzimonti, M., Sarte, P.-D. and Soares, J. (2009), 'Distortionary taxes and public investment when government promises are not enforceable', Journal of Economic Dynamics and Control 33(9), 1662-1681.

Barro, R. J. (1979), 'On the determination of the public debt', The Journal of Political Economy 87(5), 940-971.

Barro, R. J. and Gordon, D. B. (1983), 'A positive theory of monetary policy in a natural-rate model', The Journal of Political Economy 91, 589-610.

Benati, L. and Goodhart, C. (2011), Monetary policy regimes and economic performance: The historical record, 1979-2008, in B. M. Friedman and M. Woodford, eds, 'Handbook of Monetary Economics', Vol. 3B, North Holland, Amsterdam.

Berentsen, A. and Waller, C. (2011), 'Outside versus inside bonds: A Modigliani-Miller type result for liquidity constrained economies', Journal of Economic Theory 146(5), 1852-1887.

Brumm, H. J. (2006), 'The effect of central bank independence on inflation in developing countries', Economics Letters 90, 189-193.

Brumm, H. J. (2011), 'Inflation and central bank indepedence: Two-way causality?', Economics Letters 111, 220-222.

Campillo, M. and Miron, J. A. (1997), Why does inflation differ across countries?, in C. D. Romer and D. H. Romer, eds, 'Reducing Inflation: Motivation and Strategy', University of Chicago Press, pp. 335-357.

Chari, V. V., Christiano, L. J. and Kehoe, P. J. (1991), 'Optimal fiscal and monetary policy: Some recent results', Journal of Money, Credit and Banking 23(3), 519-539.

Cukierman, A. (2008), 'Central Bank independence and monetary policymaking institutionspast, present and future', European Journal of Political Economy 24, 722-736. 
Cukierman, A. and Lippi, F. (1999), 'Central bank independence, centralization of wage bargaining, inflation and unemployment: Theory and some evidence', European Economic Review 43, 1395-1434.

Debelle, G. and Fischer, S. (1994), 'How independent should a central bank be?', Conference Series, Federal Reserve Bank of Boston 38, 195-225.

Díaz-Giménez, J., Giovannetti, G., Marimón, R. and Teles, P. (2008), 'Nominal debt as a burden on monetary policy', Review of Economic Dynamics 11(3), 493-514.

Dixit, A. and Lambertini, L. (2003), 'Interactions of commitment and discretion in monetary and fiscal policies', American Economic Review 93(5), 1522-1542.

Grilli, V., Masciandaro, D. and Tabellini, G. (1991), 'Political and monetary institutions and public financial policies in the industrial countries', Economic Policy 6(13), 341-392.

Kiyotaki, N. and Moore, J. (2002), 'Evil is the root of all money', American Economic Review 92(2), 62-66.

Klein, P., Krusell, P. and Ríos-Rull, J.-V. (2008), 'Time-consistent public policy', The Review of Economic Studies 75(3), 789-808.

Kocherlakota, N. (1998), 'Money is memory', Journal of Economic Theory 81, 232-251.

Krusell, P. and Smith, A. (2003), 'Consumption-savings decisions with quasi-geometric discounting', Econometrica 71(1), 365-375.

Kydland, F. E. and Prescott, E. C. (1977), 'Rules rather than discretion: The inconsistency of optimal plans', The Journal of Political Economy 85(3), 473-491.

Lagos, R. and Wright, R. (2005), 'A unified framework for monetary theory and policy analysis', The Journal of Political Economy 113(3), 463-484.

Leeper, E. M. (1991), 'Equilibria under active and passive monetary and fiscal policies', Journal of Monetary Economics 27, 129-147.

Lohmann, S. (1992), 'Optimal commitment in monetary policy: Credibility versus flexibility', American Economic Review 82(1), 273-286.

Lucas, R. E. (2000), 'Inflation and welfare', Econometrica 68(2), 247-274.

Lucas, R. E. and Stokey, N. L. (1983), 'Optimal fiscal and monetary policy in an economy without capital', Journal of Monetary Economics 12(1), 55-93.

Martin, F. M. (2009), 'A positive theory of government debt', Review of Economic Dynamics $\mathbf{1 2}(4), 608-631$.

Martin, F. M. (2010), 'Markov-perfect capital and labor taxes', Journal of Economic Dynamics and Control 34(3), 503-521.

Martin, F. M. (2011), 'On the joint determination of fiscal and monetary policy', Journal of Monetary Economics 58(2), 132-145.

Martin, F. M. (2013), 'Government policy in monetary economies', International Economic Review 54(1), 185-217.

Maskin, E. and Tirole, J. (2001), 'Markov perfect equilibrium', Journal of Economic Theory 100(2), 191-219. 
Meltzer, A. H. (2009a), A History of the Federal Reserve, Volume 2, Book 1, 1951-1969, The University of Chicago Press.

Meltzer, A. H. (2009b), 'Learning about policy from Federal Reserve history', Cato Journal 30(2), 279-309.

Niemann, S. (2011), 'Dynamic monetary-fiscal interactions and the role of monetary conservatism', Journal of Monetary Economics 58(3), 234-247.

Niemann, S., Pichler, P. and Sorger, G. (2013), 'Central bank independence and the monetary instrument problem', International Economic Review, forthcoming .

Ortigueira, S. (2006), 'Markov-perfect optimal taxation', Review of Economic Dynamics 9, 153178.

Persson, T., Roland, G. and Tabellini, G. (2000), 'Comparative politics and public finance', The Journal of Political Economy 108(6), 1121-1161.

Persson, T. and Tabellini, G. (1998), Political economics and macroeconomic policy, in J. B. Taylor and M. Woodford, eds, 'Handbook of Macroeconomics', Vol. 1C, North Holland, Amsterdam, chapter 22 .

Posen, A. S. (1993), Why central bank independence does not cause low inflation: There is no institutional fix for politics, in R. O'Brien, ed., 'Finance and the International Economy', Vol. 7, Oxford University Press, pp. 40-65.

Primiceri, G. (2006), 'Why inflation rose and fell: Policymakers' beliefs and US postwar stabilization policy', The Quarterly Journal of Economics 121, 867-901.

Rogoff, K. (1985), 'The optimal commitment to an intermediate monetary target', The Quarterly Journal of Economics 100, 1169-1189.

Sargent, T. and Wallace, N. (1981), 'Some unpleasant monetarist arithmetic', Minneapolis Federal Reserve Bank Quarterly Review, Fall .

Shi, S. (2006), 'Viewpoint: A microfoundation of monetary economics', Canadian Journal of Economics 39(3), 643-688.

Svensson, L. E. O. (1997), 'Optimal inflation targets, "conservative" central banks, and linear inflation contracts', American Economic Review 87(1), 98-114.

Wallace, N. (2001), 'Whither monetary economics?', International Economic Review 42(4), 847869.

Waller, C. (2011), 'Independence + accountability: Why the Fed is a well-designed Central Bank', Federal Reserve Bank of St. Louis Review 93(5), 239-301.

Waller, C. J. (1992), 'The choice of a conservative central banker in a multisector economy', American Economic Review 82(4), 1006-1012.

Walsh, C. E. (1995), 'Optimal contracts for central bankers', American Economic Review 85(1), 150-167.

Walsh, C. E. (2008), Central bank independence, in S. N. Durlauf and L. E. Blume, eds, 'The New Palgrave Dictionary of Economics (2nd edition)', Palgrave Macmillan.

Wong, T.-N. (2014), A tractable monetary model under general preferences. Mimeo.

Woodford, M. (2001), 'Fiscal requirements for price stability', Journal of Money, Credit and Banking 33, 669-728. 


\section{Appendix}

\section{A Derivation of (19) and (20)}

In steady state $\left\{B^{*}, x^{*}, c^{*}, g^{*}\right\}, \lambda_{i}=\lambda_{i}^{\prime}=\lambda_{i}^{*}$ for $i=\{F, M\}$. Given $\mathcal{X}_{B}^{*} \neq 0$, the fiscal GEE (17) becomes

$$
\lambda_{F}^{*} \eta\left(u_{x x}^{*} x^{*}+u_{x}^{*}-\phi\right)+\lambda_{M}^{*} \phi\left(1+B^{*}\right)=0 .
$$

From (16), $\eta\left(u_{x}^{*}-\phi\right)=\lambda_{M}^{*} \phi\left(1+B^{*}\right)$. Replacing this expression in (23) yields (19).

The monetary GEE (18) can be written as

$$
\begin{aligned}
\lambda_{M}^{*}\left\{\eta\left(u_{x x}^{*} x^{*}+u_{x}^{*}-\phi\right)+\phi\left(1+B^{*}\right)\right\} & \mathcal{X}_{B}^{*}+\left(\lambda_{M}^{*}-\lambda_{F}^{*}\right)\left(U_{c}^{*}-\alpha+U_{c c}^{*} c^{*}\right) \mathcal{C}_{B}^{*} \\
& +\left\{\mathcal{R}_{M, g}^{*}-\mathcal{R}_{F, g}^{*}-\alpha\left(\lambda_{M}^{*}-\lambda_{F}^{*}\right)\right\} \mathcal{G}_{B}^{*}=0
\end{aligned}
$$

From (17) we have $\lambda_{F}^{*}\left\{\eta\left(u_{x x}^{*} x^{*}+u_{x}^{*}-\phi\right)+\phi\left(1+B^{*}\right)\right\}=-\left(\lambda_{M}^{*}-\lambda_{F}^{*}\right) \phi\left(1+B^{*}\right)$. Using (16) again we can rearrange this expression as

$$
\lambda_{M}^{*}\left\{\eta\left(u_{x x}^{*} x^{*}+u_{x}^{*}-\phi\right)+\phi\left(1+B^{*}\right)\right\}=-\frac{\left(\lambda_{M}^{*}-\lambda_{F}^{*}\right) \eta\left(u_{x}^{*}-\phi\right)}{\lambda_{F}^{*}} .
$$

From (13) we have

$$
U_{c}^{*}-\alpha+U_{c c}^{*} c^{*}=-\frac{\left(U_{c}^{*}-\alpha\right)}{\lambda_{F}^{*}} .
$$

Replacing (25) and (26) into (24) yields (20).

\section{B Proofs}

\section{B.1 Proof of Proposition 1}

When $\mathcal{R}_{F}(g)=\mathcal{R}_{M}(g)=\mathcal{R}(g)$, the steady state in a MPME solves

$$
\begin{aligned}
\eta\left(u_{x x}^{*} x^{*}+u_{x}^{*}-\phi\right)+\phi\left(1+B^{*}\right) & =0 \\
u_{x}^{*}-\phi+\lambda^{*}\left(u_{x x}^{*} x^{*}+u_{x}^{*}-\phi\right) & =0 \\
U_{c}^{*}-\alpha+\lambda^{*}\left(U_{c}^{*}-\alpha+U_{c c}^{*} c^{*}\right) & =0 \\
\left(U_{c}^{*}-\alpha\right) c^{*}-\alpha g^{*}+\beta \eta x^{*}\left(u_{x}^{*}-\phi\right)-(1-\beta) \phi x^{*}\left(1+B^{*}\right) & =0 .
\end{aligned}
$$

where $\lambda^{*}=\left(v_{g}^{*}-\alpha+\mathcal{R}_{g}^{*}\right) / \alpha$.

A standard approach to formulate the problem of the government with commitment is to collapse the sequence of government budget constraints into a single "implementability" constraint - see Chari et al. (1991). A simple way to derive it here is to take (11), multiply it by $\beta^{t}$ and sum over all periods. The transversality condition, $\lim _{T \rightarrow \infty} \beta^{T} \frac{U_{c, t}\left(1+\mu_{T}\right)\left(1+q_{T} B_{T+1}\right)}{p_{c, T}}=0$, implies $\lim _{T \rightarrow \infty} \beta^{T}\left\{\beta \eta x_{T+1}\left(u_{x, T+1}-\phi\right)+\beta \phi x_{T+1}\left(1+B_{T+1}\right)\right\}=0$. Thus, all terms containing debt cancel out, except for the initial period, $t=0$. After some rearrangements, we get

$$
\sum_{t=0}^{\infty} \beta^{t}\left\{\left(U_{c, t}-\alpha\right) c_{t}-\alpha g_{t}+\eta x_{t}\left(u_{x, t}-\phi\right)\right\}-\eta x_{0}\left(u_{x, 0}-\phi\right)-\phi x_{0}\left(1+B_{0}\right)=0 .
$$

Assuming $\mathcal{R}_{F}(g)=\mathcal{R}_{M}(g)=\mathcal{R}(g)$ and $B_{0} \in \Gamma$, the government solves

$$
\max _{\left\{x_{t}, c_{t}, g_{t}\right\}_{t=0}^{\infty}} \sum_{t=0}^{\infty} \beta^{t}\left\{\mathcal{U}\left(x_{t}, c_{t}, g_{t}\right)+\mathcal{R}\left(g_{t}\right)\right\}
$$


subject to (27). The first-order conditions are

$$
\begin{array}{rll}
\eta\left(u_{x, 0}-\phi\right)-\Lambda \phi\left(1+B_{0}\right) & =0, & \text { for } t=0 \\
u_{x, t}-\phi+\Lambda\left(u_{x, t}-\phi+u_{x x, t} x_{t}\right) & =0, & \text { for all } t \geq 1 \\
U_{c, t}-\alpha+\Lambda\left(U_{c, t}-\alpha+U_{c c, t} c_{t}\right) & =0, & \text { for all } t \geq 0 \\
v_{g, t}-\alpha+\mathcal{R}_{g}-\Lambda \alpha & =0, & \text { for all } t \geq 0
\end{array}
$$

where $\Lambda$ is the Lagrange multiplier associated with (27). Note that $c_{t}$ and $g_{t}$ are constant for all $t \geq 0$, while $x_{t}$ is constant for all $t \geq 1$ and may be different in the initial period. Call the corresponding allocation $\left\{x_{0}, x_{1}, c, g\right\}$. Thus, we can write $(27)$ as $\left(U_{c}-\alpha\right) c-\alpha g+\beta \eta x_{1}\left(u_{x, 1}-\right.$ $\phi)=(1-\beta) \phi x_{0}\left(1+B_{0}\right)$. Plug this expression into (11) and we get $B_{t}=\frac{x_{0}\left(1+B_{0}\right)}{x_{1}}-1$ for all $t \geq 1$, i.e., debt is constant after the initial period as well, which is a standard feature of this type of model. After some rearrangements, $\left\{x_{0}, x_{1}, c, g\right\}$ solve

$$
\begin{aligned}
\eta\left(u_{x, 0}-\phi\right)-\Lambda \phi\left(1+B_{0}\right) & =0 \\
u_{x, 1}-\phi+\Lambda\left(u_{x, 1}-\phi+u_{x x, 1} x_{1}\right) & =0 \\
U_{c}-\alpha+\Lambda\left(U_{c}-\alpha+U_{c c} c\right) & =0 \\
\left(U_{c}-\alpha\right) c-\alpha g+\beta \eta x_{1}\left(u_{x, 1}-\phi\right)-(1-\beta) \phi x_{0}\left(1+B_{0}\right) & =0,
\end{aligned}
$$

where $\Lambda=\left(v_{g}-\alpha+\mathcal{R}_{g}\right) / \alpha$.

If we set $B_{0}=B^{*}$, where $\phi\left(1+B^{*}\right)=-\eta\left(u_{x x}^{*} x^{*}+u_{x}^{*}-\phi\right)$, it is straightforward to verify that $\left\{x_{0}=x_{1}=x^{*}, c=c^{*}, g=g^{*}\right\}$ solves the above system. It then follows that $B_{t}=B^{*}$ for all $t \geq 0$.

\section{B.2 Proof of Proposition 2}

As $v_{g}+\mathcal{R}_{F, g} \rightarrow \psi_{F}, \lambda_{F} \rightarrow \lambda_{F}^{*}=\frac{\psi_{F}}{\alpha}-1>0$ for all $B \in \Gamma$. Thus, (13) implies $\mathcal{C}(B)=c^{*}$ for all $B \in \Gamma$.

Assuming $\mathcal{X}_{B}<0$ (which is verified below), the fiscal GEE (17) simplifies to $\lambda_{F}^{*} \eta\left(u_{x x}^{\prime} x^{\prime}+\right.$ $\left.u_{x}^{\prime}-\phi\right)+\lambda_{M}^{\prime} \phi\left(1+B^{\prime}\right)=0$. Using (16) and rearranging we obtain

$$
\left(1+\lambda_{F}^{*}\right)\left(u_{x}^{\prime}-\phi\right)+\lambda_{F}^{*} u_{x x}^{\prime} x^{\prime}=0 .
$$

Given $x^{\prime}=\mathcal{X}\left(B^{\prime}\right)$ and $\mathcal{X}_{B}<0$, the fiscal GEE is solved by the same $B^{\prime}$ regardless of $B$, i.e., $\mathcal{B}(B)$ is a constant. Define $B^{*}$ such that $\mathcal{B}\left(B^{*}\right)=B^{*}$ and thus, $\mathcal{B}(B)=B^{*}$ for all $B \in \Gamma$. Since $x^{\prime}=\mathcal{X}\left(B^{\prime}\right)=\mathcal{X}\left(B^{*}\right)=x^{*}$, the fiscal GEE (28) implies

$$
-\frac{u_{x}^{*}-\phi}{u_{x x}^{*} x^{*}}=\frac{\lambda_{F}^{*}}{1+\lambda_{F}^{*}} .
$$

Since $\lambda_{F}^{*}>0$, the condition above implies $u_{x}^{*}-\phi>0$. By (9), $q<1$ and by (16), $\lambda_{M}^{\prime}=\lambda_{M}^{*}>0$ and $B^{*}>-1$.

Given $B^{\prime}=B^{*}, x^{\prime}=x^{*}, \lambda_{F}^{\prime}=\lambda_{F}^{*}$ and $\lambda_{M}^{\prime}=\lambda_{M}^{*}$, the monetary GEE (18) implies the same solution for $\lambda_{M}$ for all $B \in \Gamma$. Thus, $\lambda_{M}=\lambda_{M}^{*}>0$ for all $B \in \Gamma$. From (16), we have $\eta\left(u_{x}-\phi\right)=\lambda_{M} \phi(1+B)$ and $\eta\left(u_{x}^{*}-\phi\right)=\lambda_{M}^{*} \phi\left(1+B^{*}\right)$. Thus, given $\lambda_{M}=\lambda_{M}^{*}, \mathcal{X}(B)$ solves

$$
u_{x}-\phi=\frac{\left(u_{x}^{*}-\phi\right)(1+B)}{1+B^{*}} .
$$

Differentiating (30) with respect to $B$ and using $\mathcal{B}_{B}=0$, as shown above, we obtain

$$
\mathcal{X}_{B}=\frac{u_{x}^{*}-\phi}{u_{x x}\left(1+B^{*}\right)}
$$


Since $u_{x}^{*}-\phi>0$, we verify $\mathcal{X}_{B}<0$ for all $B \in \Gamma$.

Take the government budget constraint (11), written compactly as $\varepsilon\left(B, B^{\prime}, x, x^{\prime}, c, g\right)=0$. Differentiating with respect to $B$, we obtain $\varepsilon_{B}+\varepsilon_{B^{\prime}} \mathcal{B}_{B}+\varepsilon_{x} \mathcal{X}_{B}+\varepsilon_{x^{\prime}} \mathcal{X}_{B}^{\prime} \mathcal{B}_{B}+\varepsilon_{c} \mathcal{C}_{B}+\varepsilon_{g} \mathcal{G}_{B}=0$ for all $B \in \Gamma$. Since $\mathcal{B}_{B}=\mathcal{C}_{B}=0$, we get: $-\phi x-\phi(1+B) \mathcal{X}_{B}-\alpha \mathcal{G}_{B}=0$. Using the expression for $\mathcal{X}_{B}$ derived above, we obtain

$$
\mathcal{G}_{B}=-\frac{\phi x}{\alpha}\left\{1+\frac{\left(u_{x}^{*}-\phi\right)(1+B)}{u_{x x} x\left(1+B^{*}\right)}\right\},
$$

which using (29) implies $\mathcal{G}_{B}^{*}=-\frac{\phi x^{*}}{\alpha\left(1+\lambda_{F}^{*}\right)}<0$.

Given $\lambda_{M}=\lambda_{M}^{\prime}=\lambda_{M}^{*}$, the monetary GEE (18) is evaluated at $B^{\prime}=B^{*}$ for all $B \in \Gamma$ and does not depend on $B$. Thus, it is always evaluated steady state, for any current level of debt, as expressed in (20). Given $C_{B}^{*}=0,(20)$ simplifies to

$$
\left(\lambda_{M}^{*}-\lambda_{F}^{*}\right) \eta\left(u_{x}^{*}-\phi\right) \mathcal{X}_{B}^{*}=\lambda_{F}^{*}\left\{R_{M, g}^{*}-R_{F, g}^{*}-\alpha\left(\lambda_{M}^{*}-\lambda_{F}^{*}\right)\right\} \mathcal{G}_{B}^{*}
$$

Using (31) and (32) evaluated at $B^{*}$ and (16) we can rearrange the above expression as

$$
\left(\lambda_{M}^{*}-\lambda_{F}^{*}\right) \frac{\lambda_{M}^{*}\left(u_{x}^{*}-\phi\right)}{u_{x x}^{*} x^{*}}=-\frac{\lambda_{F}^{*}}{\alpha\left(1+\lambda_{F}^{*}\right)}\left\{R_{M, g}^{*}-R_{F, g}^{*}-\alpha\left(\lambda_{M}^{*}-\lambda_{F}^{*}\right)\right\} .
$$

Using (29) we obtain

$$
\alpha\left(1+\lambda_{M}^{*}\right)\left(\lambda_{M}^{*}-\lambda_{F}^{*}\right)-\left(\mathcal{R}_{M, g}^{*}-\mathcal{R}_{F, g}^{*}\right)=0 .
$$

A MPME is characterized by $\left\{\mathcal{B}(B)=B^{*}, \mathcal{X}(B), \mathcal{C}(B)=c^{*}, \mathcal{G}(B)\right\}$ satisfying (11), (13), (30) and (33) for all $B \in \Gamma$, given $x^{*}$ solving $(29), \lambda_{F}^{*}=\frac{\psi_{F}}{\alpha}-1$ and $\lambda_{M}^{*}=\frac{\eta\left(u_{x}^{*}-\phi\right)}{\phi\left(1+B^{*}\right)}$. Uniqueness of the equilibrium follows from the properties of $u(x), U(c)$ and $\mathcal{R}_{i}(g)$.

\section{B.3 Proof of Proposition 3}

The monetary GEE (33) becomes: $\alpha\left(1+\lambda_{M}^{*}\right)\left(\lambda_{M}^{*}-\lambda_{F}^{*}\right)=\omega_{M}^{-1}-\omega_{F}^{-1}$. Given $\lambda_{F}^{*}=\frac{\psi+\omega_{F}^{-1}}{\alpha}-1$, which does not depend on $\omega_{M}$, and that both $\lambda_{M}^{*}$ and $\lambda_{F}^{*}$ are positive, (33) implies $\lambda_{M}^{*}$ is strictly decreasing in $\omega_{M}$. Therefore, given $\lambda_{M}^{*}=\frac{\eta\left(u_{x}^{*}-\phi\right)}{\phi\left(1+B^{*}\right)}$ and that $x^{*}$ does not depend on $\omega_{M}$, $\mathcal{B}(B)=B^{*}$ is strictly increasing in $\omega_{M}$ for all $B \in \Gamma$.

From (30), $B^{*}$ strictly increasing in $\omega_{M}$ implies that $\mathcal{X}(B)$ is strictly increasing in $\omega_{M}$ for all $B \in \Gamma$. Consider the money growth rate according to (6). Given that $\mathcal{X}(B)$ is strictly increasing in $\omega_{M}$ while $x^{*}$ is invariant, $\mu$ decreases for any $B \in \Gamma$, while $\mu^{*}$ remains the same.

In steady state, the government budget constraint (11) implies $\alpha g^{*}=\left(U_{c}^{*}-\alpha\right) c^{*}+\beta \eta x^{*}\left(u_{x}^{*}-\right.$ $\phi)-(1-\beta) \phi x^{*}\left(1+B^{*}\right)$. Given that $x^{*}$ and $c^{*}$ do not depend on $\omega_{M}$ and $B^{*}$ is strictly increasing in $\omega_{M}, g^{*}$ is strictly decreasing in $\omega_{M}$. Using (7), (8) and the night-resource constraint, the primary deficit, defined as $p_{c}^{*}\left(g^{*}-\tau^{*} n^{*}\right)$, is equal to $\frac{\alpha g^{*}-\left(U_{c}^{*}-\alpha\right) c^{*}}{\phi x^{*}}$ and so, is strictly decreasing in $\omega_{M}$.

\section{B.4 Proof of Proposition 4}

Given (22), the government budget constraint can be rearranged as:

$$
\frac{\alpha g-\left(U_{c}-\alpha\right) c}{\phi x_{T}}=\beta \eta\left(1 / \omega_{T}-1\right)-(1-\beta)(1+B),
$$

where $x_{T}$ solves (22). From the monetary equilibrium conditions, (6)-(9), the left-hand side is equal to the primary deficit, $p_{c}(g-\tau n)$. The right-hand side is strictly decreasing in $\omega_{T}$ and does not depend on $\mathcal{R}_{F}(g)$. 